\title{
Isoprene and monoterpene fluxes from Central Amazonian rainforest inferred from tower-based and airborne measurements, and implications on the atmospheric chemistry and the local carbon budget
}

\author{
U. Kuhn ${ }^{1}$, M. O. Andreae ${ }^{1}$, C. Ammann ${ }^{2}$, A. C. Araújo ${ }^{3}$, E. Brancaleoni ${ }^{4}$, P. Ciccioli ${ }^{4}$, T. Dindorf ${ }^{1}$, M. Frattoni ${ }^{4}$, \\ L. V. Gatti ${ }^{5}$, L. Ganzeveld ${ }^{6}$, B. Kruijt ${ }^{7}$, J. Lelieveld ${ }^{6}$, J. Lloyd ${ }^{8, *}$, F. X. Meixner ${ }^{1}$, A. D. Nobre ${ }^{3}$, U. Pöschl ${ }^{1}$, C. Spirig ${ }^{2}$, \\ P. Stefani ${ }^{9}$, A. Thielmann ${ }^{1}$, R. Valentini ${ }^{9}$, and J. Kesselmeier ${ }^{1}$ \\ ${ }^{1}$ Max Planck Institute for Chemistry, Biogeochemistry Dept., Mainz, Germany \\ ${ }^{2}$ Federal Research Station for Agroecology and Agriculture, Zürich, Switzerland \\ ${ }^{3}$ Instituto Nacional de Pesquisas da Amazônia (INPA), Manaus, Brazil \\ ${ }^{4}$ Istituto di Metodologie Chimiche, Area delle Ricerca di Roma, Monterot. Scalo, Italy \\ ${ }^{5}$ Instituto de Pesquisas Energeticas e Nucleares (IPEN), São Paulo, Brazil \\ ${ }^{6}$ Max Planck Institute for Chemistry, Atmospheric Chemistry Dept., Mainz, Germany \\ ${ }^{7}$ Alterra, Wageningen University and Research Centre, Wageningen, Netherlands \\ ${ }^{8}$ Max Planck Institute for Biogeochemistry, Jena, Germany \\ ${ }^{9}$ University of Tuscia, Department of Forest Science and Environment, Viterbo, Italy \\ *now at: Earth and Biosphere Institute, School of Geography, University of Leeds, UK
}

Received: 1 December 2006 - Published in Atmos. Chem. Phys. Discuss.: 16 January 2007

Revised: 14 May 2007 - Accepted: 22 May 2007 - Published: 11 June 2007

\begin{abstract}
We estimated the isoprene and monoterpene source strengths of a pristine tropical forest north of Manaus in the central Amazon Basin using three different micrometeorological flux measurement approaches. During the early dry season campaign of the Cooperative LBA Airborne Regional Experiment (LBA-CLAIRE-2001), a towerbased surface layer gradient (SLG) technique was applied simultaneously with a relaxed eddy accumulation (REA) system. Airborne measurements of vertical profiles within and above the convective boundary layer (CBL) were used to estimate fluxes on a landscape scale by application of the mixed layer gradient (MLG) technique. The mean daytime fluxes of organic carbon measured by REA were $2.1 \mathrm{mg} \mathrm{C} \mathrm{m}^{-2} \mathrm{~h}^{-1}$ for isoprene, $0.20 \mathrm{mg} \mathrm{C} \mathrm{m}^{-2} \mathrm{~h}^{-1}$ for $\alpha$ pinene, and $0.39 \mathrm{mg} \mathrm{C} \mathrm{m}^{-2} \mathrm{~h}^{-1}$ for the sum of monoterpenes. These values are in reasonable agreement with fluxes determined with the SLG approach, which exhibited a higher scatter, as expected for the complex terrain investigated. The observed VOC fluxes are in good agreement with simulations using a single-column chemistry and climate model (SCM).

In contrast, the model-derived mixing ratios of VOCs
\end{abstract}

Correspondence to: U. Kuhn

(kuhn@mpch-mainz.mpg.de) were by far higher than observed, indicating that chemical processes may not be adequately represented in the model. The observed vertical gradients of isoprene and its primary degradation products methyl vinyl ketone (MVK) and methacrolein (MACR) suggest that the oxidation capacity in the tropical CBL is much higher than previously assumed. A simple chemical kinetics model was used to infer $\mathrm{OH}$ radical concentrations from the vertical gradients of (MVK+MACR)/isoprene. The estimated range of $\mathrm{OH}$ concentrations during the daytime was 3$8 \times 10^{6}$ molecules $\mathrm{cm}^{-3}$, i.e., an order of magnitude higher than is estimated for the tropical CBL by current state-of-theart atmospheric chemistry and transport models. The remarkably high $\mathrm{OH}$ concentrations were also supported by results of a simple budget analysis, based on the flux-to-lifetime relationship of isoprene within the CBL. Furthermore, VOC fluxes determined with the airborne MLG approach were only in reasonable agreement with those of the tower-based REA and SLG approaches after correction for chemical decay by $\mathrm{OH}$ radicals, applying a best estimate $\mathrm{OH}$ concentration of $5.5 \times 10^{6}$ molecules $\mathrm{cm}^{-3}$. The SCM model calculations support relatively high $\mathrm{OH}$ concentration estimates after specifically being constrained by the mixing ratios of chemical constituents observed during the campaign. 
The relevance of the VOC fluxes for the local carbon budget of the tropical rainforest site during the measurements campaign was assessed by comparison with the concurrent $\mathrm{CO}_{2}$ fluxes, estimated by three different methods (eddy correlation, Lagrangian dispersion, and mass budget approach). Depending on the $\mathrm{CO}_{2}$ flux estimate, $1-6 \%$ or more of the carbon gained by net ecosystem productivity appeared to be re-emitted through VOC emissions.

\section{Introduction}

The Amazon Basin, one of the most productive terrestrial ecosystems of the Earth, plays an important role in global atmospheric chemistry and physics, and any change in the atmospheric chemical processes in this area can have a profound impact on global climate (Andreae and Crutzen, 1997). Photochemical reactions of volatile organic compounds (VOCs) have a significant influence on atmospheric ozone $\left(\mathrm{O}_{3}\right)$, the hydroxyl radical $(\mathrm{OH})$, precipitation acidity, and aerosol formation, among others. Previous studies have indicated that the influence of isoprene and monoterpene reactions on important aspects of atmospheric chemistry can be substantial, as these compounds play an important role in shaping the odd hydrogen photochemistry and regional ozone production of remote areas (Goldan et al., 2000). The dominating role of biogenic VOCs in the chemistry of the lower troposphere is due to (i) their greater abundance in remote areas, especially in the tropics, and (ii) their high atmospheric reactivity compared to the majority of anthropogenic VOCs (Fuentes et al., 2000).

The principal oxidizing agent in the troposphere that dominates the daytime removal of most gaseous pollutants is the $\mathrm{OH}$ radical, which can be conceived as a measure for the self-cleansing capacity of the atmosphere, and is therefore dubbed the "detergent" of the atmosphere (Andreae and Crutzen, 1997). It governs the atmospheric lifetime of VOCs, carbon monoxide (CO), as well as of the greenhouse gases methane $\left(\mathrm{CH}_{4}\right)$, HCFCs, and $\mathrm{CH}_{3} \mathrm{Br}$, and thus maintains the chemical composition of the atmosphere. The production of $\mathrm{OH}$ radicals is believed to occur largely via photolysis of ozone followed by subsequent reaction of the emerging $\mathrm{O}\left({ }^{1} \mathrm{D}\right)$ with water vapour and by photolysis of formaldehyde (HCHO) (Tan et al., 2001). The production of OH radicals is at the maximum in the tropics, as the ingredients (UV radiation and water vapour) are at a high level. Hence the tropical troposphere is assumed to be responsible for the major share of the global atmospheric oxidation of long-lived gases. However, current atmospheric chemistry models tend to predict that high mixing ratios of VOCs cause substantial reductions in $\mathrm{OH}$ radical concentration in the lower troposphere of tropical areas (e.g. Warneke et al., 2001; Lelieveld et al., 2004), and real measurements of $\mathrm{OH}$ radical concentrations in the "Great Tropical Reactor" are not yet available.
Furthermore, tropical forest ecosystems play a major role in global carbon sequestration (Tian et al., 1998; Botta et al., 2002). A fraction of the assimilated carbon is reemitted as VOCs by terrestrial vegetation. While VOC emissions may be small in relation to net primary productivity (NPP), the amount of carbon lost as VOC emissions can be significant relative to the net ecosystem productivity (NEP) or net biome productivity (NBP), respectively (Guenther et al., 1995; Guenther, 2002; Kesselmeier et al., 2002). On a global scale VOCs are emitted at an estimated $1.2 \mathrm{Pg} \mathrm{Ca}^{-1}$ (Guenther et al., 1995), a number of the same magnitude as the mean annual increase of $\mathrm{CO}_{2}$ in the earth's atmosphere, and the carbon sink by the terrestrial biosphere (3.2 and $2.4 \mathrm{Pg} \mathrm{Ca}^{-1}$, respectively; ICPP 2001). Isoprene and monoterpenes are estimated to account for the major share of VOC emissions, and tropical vegetation constitutes their largest single source (Guenther et al., 1995).

Considering the importance of tropical ecosystems on atmospheric processes, global carbon sequestration, and VOC emission strength, available data on the exchange of VOCs in these regions are still scarce. In view of the vast biodiversity of tropical forest ecosystems, with an estimated 35000 species of angiosperms in the Amazon Basin alone, the extrapolation of single species-specific exchange studies based on the leaf and branch level can hardly be sufficient to adequately characterize landscape exchange rates. Tower-based and airborne multi-scale micrometeorological flux measurement techniques can quantitatively integrate emissions at the landscape scale in a more representative manner. Several recent studies have considered VOC fluxes, but still the significance of VOC exchange between tropical terrestrial ecosystems and the atmosphere in regional and global carbon cycling remains poorly understood (Zimmermann et al., 1988; Rasmussen and Khalil, 1988; Helmig et al., 1998; Serca et al., 2001; Geron et al., 2002; Rinne et al., 2002; Greenberg et al., 2004; Karl et al., 2004).

The Cooperative LBA Airborne Regional Experiment (LBA-CLAIRE) project forms part of a series of integrated airborne and ground-based campaigns, as part of the Large-scale Biosphere-Atmosphere Experiment in Amazonia (LBA). During the intensive LBA-CLAIRE 2001 campaign, continuous tower-based relaxed eddy accumulation (REA) observations of canopy-scale VOC fluxes in a remote tropical rainforest site north of Manaus were run simultaneously with measurements using a surface layer gradient (SLG) flux approach. Both methods integrate over an upwind footprint area of typically $2-3 \mathrm{~km}^{2}$, but do not integrate the large-scale spatial diversity of the tropical rain forest, with clearings, rivers and the vast biodiversity of vegetation species composition. In addition, VOC vertical profiles within and above the convective boundary layer (CBL) were investigated by aircraft measurements. These were used to infer VOC fluxes on a landscape scale by application of a mixed layer gradient (MLG) approach, which, however, involves other uncertainties, such as an increased influence of 
the assumptions made on boundary layer turbulence, dynamics, and atmospheric chemistry. For reactive scalars like biogenic VOCs the timescale of atmospheric chemistry may be similar to the convective eddy turnover time.

Our results seek to contribute to a better understanding of the source strength, the persistence, and fate of biogenic VOCs in the atmosphere of the Amazon Basin, and the role of this region in the global atmospheric chemistry and carbon cycle. The main questions addressed in this work are (i) what is the magnitude of the VOC emission strength, (ii) what is the relative contribution of the VOC emission with respect to ecosystem carbon exchange, and (iii) do current chemistry models accurately predict VOC emission fluxes, mixing ratios, and their fate in the tropical atmosphere with regard to the oxidation capacity?

\section{Material and methods}

\subsection{Site characterization}

To assess the regional VOCs and carbon balance, direct flux and profile measurements were carried out in the Reserva Biologica do Cuieiras, an undisturbed mature lowland rain forest reserve of the Instituto Nacional de Pesquisas da Amazônia (INPA) (Andreae et al., 2002). Tower-based flux data were collected from a $52 \mathrm{~m}$ walk-up scaffolding tower (K34), located on a medium sized plateau at $2^{\circ} 35^{\prime} 33^{\prime \prime} \mathrm{S}$; $60^{\circ} 12^{\prime} 27^{\prime \prime} \mathrm{W}$, about $60 \mathrm{~km}$ NNW of the city of Manaus, in central Amazonia (Fig. 1). The K34 tower has been operational for eddy correlation $\mathrm{CO}_{2}$ flux estimates since July 1999.

In general this area exhibits a small-scale relief of plateaus and lowlands that has favoured a pattern of dense vegetation with higher trees located on the plateaus and a palm-rich open forest in the lowlands (Ribeiro et al., 1999). As demonstrated by Araújo et al. (2002), the footprint of the Cuieiras site shows a relatively low fraction of plateaus ( $40 \%$ within $1 \mathrm{~km}$ radius). The old-growth tropical wet forest canopy has a height of approximately $35 \mathrm{~m}$ (Roberts et al., 1996), a total single sided leaf area index (LAI) of 4.6, and a maximum leaf area density of 0.65 at mean canopy height (Simon et al., 2005). These values are in good agreement with LAI values of 4-6 estimated by other authors for terra firme forest ecosystems (e.g. McWilliam et al., 1993; Kruijt et al., 2000; Andreae et al., 2002). Even though tree demography is extremely complex due to the vast biodiversity, the Lecythidaceae, Sapotaceae, Euphorbiaceae and Caesalpinaceae families are found most frequently (Jardim and Hosokawa, 1987). Above-ground dry phytomass has been estimated at $344-393 \mathrm{Mg} \mathrm{ha}^{-1}$ (Klinge et al., 1975) in this forest. A more recent paper reports fresh above-ground phytomass of $561 \mathrm{Mg} \mathrm{ha}^{-1}$, a basal area of $29 \mathrm{~m}^{2} \mathrm{ha}^{-1}$, and phytomass volumes of $438 \mathrm{~m}^{3} \mathrm{ha}^{-1}$ (Higuchi et al., 1998). The soils in this area are characterized as a yellow clay latosol (Brazil-

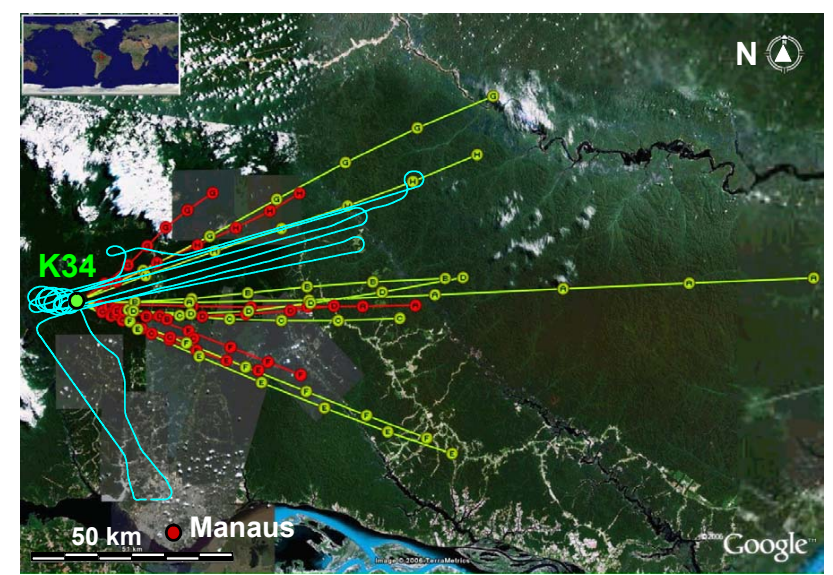

Fig. 1. Overview of the measuring site, with pristine rainforest in the majority of the footprint area of the tower-based (K34) and airborne measurements, respectively. The solid lines with dots represent the 6-h back-trajectories calculated for the individual time periods of the flight measurements, for $100 \mathrm{~m}$ (red) and $500 \mathrm{~m}$ (green) heights above the K34 tower site using the output of the HYSPLIT model (NOAA Air Resources Laboratory) as an overlay on Google Earth (Google Earth ${ }^{\mathrm{TM}}$ mapping service). The cyan line represents the typical flight pattern, which consisted of a continuous spiral up from $>50 \mathrm{~m}$ to $>3000 \mathrm{~m}$ in altitude in the vicinity of the K34 tower, followed by a stepwise descending pattern with 6 flight legs, one on top of the other.

ian classification) or oxisol (U.S. classification), with clay and sand contents of $80 \%$ and $10 \%$, respectively. Hodnett et al. (1996) calculate the available water capacity to be about $70 \mathrm{~mm} \mathrm{~m}^{-1}$ in the upper meter and about $30 \mathrm{~mm} \mathrm{~m}^{-1}$ below $2 \mathrm{~m}$. They estimated that the maximum water uptake below $2 \mathrm{~m}$ depth by vegetation can reach $250 \mathrm{~mm}$ in a dry year. The climate at this site is characterized by little seasonal variation in temperature and solar radiation and a large seasonal variation in rainfall. A short dry season from July to October occurs when the Intertropical Convergence Zone (ITCZ) is at its northern extreme. Details of the site are described in Malhi et al. (1998, 2002), Araújo et al. (2002), and Andreae et al. (2002).

\subsection{Trace gas collection and analysis}

Three different sampling/analysis systems were used to measure VOCs. For most of the measurements, ambient air samples were collected on solid adsorbents for off-line analysis in the lab. The majority of airborne and all groundbased SLG samples were collected on 2-bed graphitic carbon adsorbents and analyzed using a thermal desorption gas chromatograph with a flame ionization detector (GC-FID) as described in Kuhn et al. (2002; 2004a). Samples were collected by drawing air through fused silica-lined stainless steel cartridges $(89 \mathrm{~mm}$ length, $5.33 \mathrm{~mm}$ I.D., Silicosteel, Restek, USA) packed with sequential adsorbent beds 


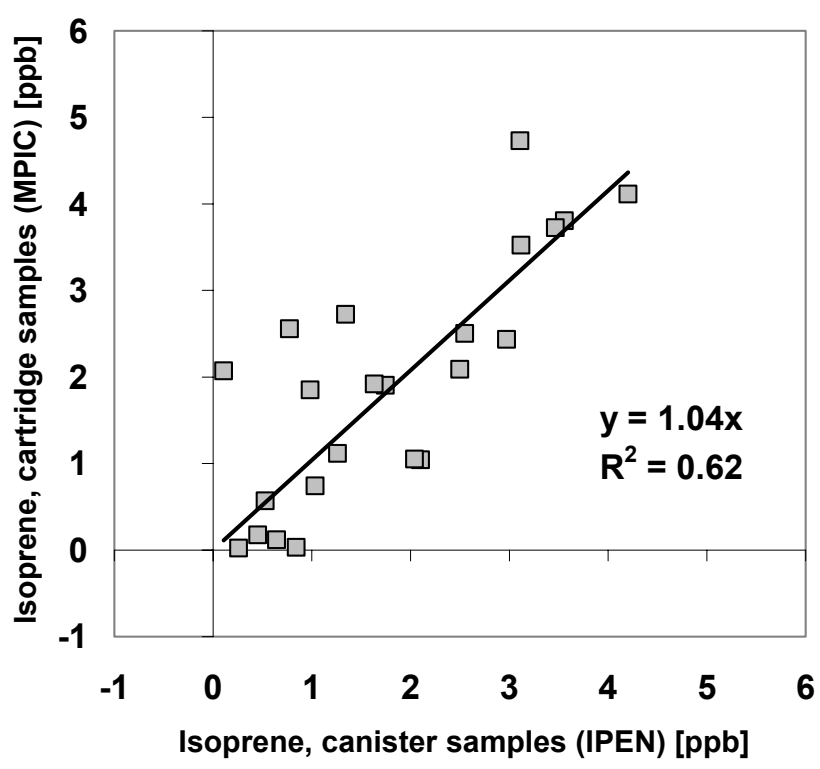

Fig. 2. Comparison of isoprene mixing ratios observed during airborne measurements by solid sorbent cartridge sample collection (MPIC) and by canister sample collections (IPEN), analyzed by different GC-FID systems.

of $130 \mathrm{mg}$ Carbograph $1\left(90 \mathrm{~m}^{2} \mathrm{~g}^{-1}\right.$, Lara s.r.l., Rome, Italy) followed by $130 \mathrm{mg}$ Carbograph $5\left(560 \mathrm{~m}^{2} \mathrm{~g}^{-1}\right)$. For the GC-FID technique, calibration was accomplished by use of different gaseous standards containing isoprene, several n-alkanes, methyl vinyl ketone (MVK), and methacrolein (MACR). The detection limit of the method was estimated as the greater of the variability in the blank levels (at the $95 \%$ confidence level, i.e., 1.96 times the standard deviation of all blank values), or a chromatographic peak three times the standard deviation of the background noise in the base line of the chromatograph. Variability in the blank usually determined the detection limit, which was typically $30 \mathrm{ppt}$ for isoprene and $10 \mathrm{ppt}$ for monoterpenes. Hence, typical uncertainties reached $10 \%$ for isoprene at $1 \mathrm{ppb}$ and ranged from 5 to $30 \%$ at $100 \mathrm{ppt}$ for monoterpenes, depending on the individual monoterpene peak resolution and blank variability.

All REA samples were accumulated on cartridges filled with three graphitic carbon adsorbents according to Brancaleoni et al. (1999). VOC were collected using glass cartridges (160mm length, $3 \mathrm{~mm}$ I.D.) packed with $118 \mathrm{mg}$ Carbopack $\mathrm{C}\left(12 \mathrm{~m}^{2} \mathrm{~g}^{-1}\right.$, Supelco, Bellefonte, USA), $60 \mathrm{mg}$ Carbograph $1\left(90 \mathrm{~m}^{2} \mathrm{~g}^{-1}\right.$, Lara s.r.l., Rome, Italy), and $115 \mathrm{mg}$ Carbograph $5\left(560 \mathrm{~m}^{2} \mathrm{~g}^{-1}\right)$ in sequential beds. They were analyzed by thermal desorption gas chromatography with mass spectrometric analysis (GC-MS). Positive identification and quantitative determinations of all VOCs from $\mathrm{C}_{4}$ to $\mathrm{C}_{16}$ carbon atoms were accomplished by running the mass spectrometer in the scan mode and by using reconstructed mass chromatography on specific ions for selective detection. Re- tention features and selective ions of biogenic VOCs, their degradation products, calibration and quality assurance procedures are described in detail in Ciccioli et al. (2002). The detection limits were in the same range as for GC-FID analysis. Dominant monoterpene species detected by both solid adsorbent analytical systems (CG-FID and GC-MS) were $\alpha$ pinene, $\beta$-pinene, myrcene, limonene, and $\rho$-cymene.

For airborne measurements, stainless steel canisters of $6 \mathrm{~L}$ volume were used as an additional backup system for isoprene analysis. These canister samples were analyzed with a gas chromatograph equipped with a FID and coupled MS according to Trostdorf et al. (2004). Reasonable agreement was achieved for isoprene mixing ratios derived by cartridges analyzed with GC-FID and canister samples (Fig. 2). The correlation analysis reveals a relatively high scatter, but an excellent agreement in the mean of both data sets (slope $=1.04$; $R^{2}=0.62$ ). In general a high scatter is expected from the snap-shot sampling characteristic of the canister technique compared to cartridge ( $15 \mathrm{~min}$, at flow rates of $200 \mathrm{ml} \mathrm{min}^{-1}$ ) sampling, with short sampling intervals being less representative for mean CBL mixing ratios. Individual downdrafts and updrafts may contain substantially different mixing ratios. Deviations from an ideal atmospheric gradient may be observed if the sample collection period is shorter than the average convective turnover time, i.e., if sampling times do not integrate over several large eddies. With typical horizontal wind speeds of $5 \mathrm{~m} \mathrm{~s}^{-1}$, and the scale of some convective eddies being as large as the CBL depth, minimum sample times of 15-30 min, or length of several hundred meters are needed to integrate over a representative air mass (Lenschow et al., 1980; Lenschow and Stankov 1986). The cartridges analyzed with GC-MS, which were collected simultaneously with cartridges analyzed by GC-FID ( 2 of 8 flights), also showed excellent agreement for monoterpene mixing ratios. For isoprene, however, they indicated similar trends in vertical profiles, but with a systematic relative underestimation of the absolute mixing ratios by a factor of 0.55 . Since these differences cannot be explained, and no systematic difference was found comparing isoprene mixing ratios derived by the GC-FID (SLG) and GC-MS (REA) during the tower-based measurements, it was decided to use the airborne isoprene data derived by GC-FID to calculate VOC fluxes from the MLG approach, based on purely statistical considerations.

\subsection{Ground-based flux measurements}

Isoprene and monoterpene fluxes from the forest canopy were calculated from ambient air measurements using different micrometeorological approaches, namely, the relaxed eddy accumulation (REA) and the surface layer gradient (SLG) techniques. The $\mathrm{CO}_{2}$ eddy covariance (EC) fluxes, and concentration profiles of $\mathrm{CO}_{2}, \mathrm{H}_{2} \mathrm{O}$, temperature, and momentum at the K34 site were part of a long-term monitoring project described in detail by Araújo et al. (2002). The VOC-REA system with a reversed geometry (Ciccioli et 
al., 2003), was installed at a height of $21 \mathrm{~m}$ above the mean canopy top. Equations used for calculating VOC fluxes are described in detail in Valentini et al. (1997) and Ciccioli et al. (2003). Only those cases were accepted, in which hourly averaged values of the vertical wind $(w)$ were close to zero (between -0.45 and $+0.45 \mathrm{~m} \mathrm{~s}^{-1}$ ) and the volume accumulated in the updraft and downdraft traps did not differ more than $10 \%$. From the experience gathered at this site, we have found that the sampling volumes were balanced best if a threshold of $\pm 0.65 \sigma(w)$ was used. This means that air was sampled through the updraft (or downdraft) cartridge only if the instantaneous vertical windspeed exceeded this threshold. In the conditions selected, the volume diverted in the two reservoirs ranged between 50 to $60 \%$ of the total volume. Monitoring VOC fluxes by REA is part of a long-term project aimed at assessing the seasonality of VOC fluxes in relation to $\mathrm{CO}_{2}$ exchange.

In the period of 17-25 July 2001, the REA flux measurements were complemented by canopy-scale flux measurements using the surface layer gradient (SLG) approach. Both methods were based on VOC collection on solid adsorbent cartridges, with simultaneous sample periods of $30 \mathrm{~min}$, and a mass flow of $150 \mathrm{ml} \mathrm{min}^{-1}$. For SLG samples, VOCs were collected on the tower at four different heights simultaneously (51, 42.5, 35.5, $28 \mathrm{~m}$ above ground) on an hourly basis using automated VOC sampling systems that are described in detail by Kuhn et al. (2005). Test samplings with all four inlets mounted at the same height showed that the samplers did not produce any bias exceeding the analytical uncertainty. VOC fluxes have been estimated according to the classical aerodynamic method (Hicks et al., 1987; Ammann, 1999) as the product of vertical surface layer VOC gradients and the turbulent transfer velocity, $V_{t r}$. The vertical VOC gradient has been determined as the difference between the two uppermost VOC concentration measurements $\left(z_{2}=51 \mathrm{~m}\right.$ and $z_{1}=42.5 \mathrm{~m}$ above ground), which had the greatest distance from the canopy top ( $h_{c}=35 \mathrm{~m}$ above ground). $V_{t r}$, is simply the inverse of the aerodynamic resistance $R_{a}$ between the two measurement heights, namely

$$
R_{a}=V_{t r}^{-1}=\left(\kappa u_{*}\right)^{-1} \times\left[\ln \left(\frac{z_{r, 2}}{z_{r, 1}}\right)-\Psi_{H}\left(\frac{z_{r, 2}}{L}\right)+\Psi_{H}\left(\frac{z_{r, 1}}{L}\right)\right]
$$

where $\kappa$ is the von Karman constant $(=0.4), u_{*}$ is the friction velocity $\left(\mathrm{m} \mathrm{s}^{-1}\right), z_{r, i}=z_{i}-d$ is the relative height $(\mathrm{m})$, $d=0.75 h_{c}$ is the so-called zero-plane displacement height (m), $\Psi_{H}\left(z_{r, i} / L\right)$ is the dimensionless integrated similarity function (or integrated stability correction function) for heat (Hicks et al., 1987), and $L$ is the Obukhov length (m) given by

$L=-\frac{T_{v} \times u_{*}^{3} \times c_{p} \times \rho_{\mathrm{air}}}{\kappa \times g \times H}$

where $T_{v}$ is the virtual temperature, $c_{p}$ is the specific heat of air at constant pressure, $g$ the acceleration of gravity $\left(\mathrm{m} \mathrm{s}^{-2}\right)$, and $H$ the turbulent sensitive heat flux $\left(\mathrm{W} \mathrm{m}^{-2}\right)$. The quantities $T_{v}, u_{*}$, and $H$ have been provided by the measurements of a sonic anemometer which is part of the $\mathrm{CO}_{2}$ and $\mathrm{H}_{2} \mathrm{O}$ eddy covariance system at the K34 tower. VOC fluxes have been calculated according to

$$
F_{\mathrm{VOC}}=V_{t r} \times\left[C_{\mathrm{VOC}}\left(z_{r, 2}\right)-C_{\mathrm{VOC}}\left(z_{r, 1}\right)\right]
$$

The following criteria have been applied to reduce unavoidable noise of flux estimates

$$
-1<\frac{z_{r, i}}{L}+1, \quad \text { and } \quad \frac{C_{\mathrm{VOC}}\left(z_{r, 2}\right)-C_{\mathrm{VOC}}\left(z_{r, 1}\right)}{\left(C_{\mathrm{VOC}}\left(z_{r, 2}\right)+C_{\mathrm{VOC}}\left(z_{r, 1}\right)\right) / 2} \leq 1
$$

Applying the SLG approach within the roughness layer of the forest may underestimate the flux rates (e.g. Garratt, 1980). The importance of this effect is dependent on canopy structures and surface characteristics (Simpson et al., 1998) and was not accounted for in the present study. This way the fluxes calculated by SLG are assumed to be a lower bound estimate. According to the footprint analysis of Araujo et al. (2002) the measured daytime fluxes at the K34 tower are representative of a $2-3 \mathrm{~km}^{2}$ area around the tower, although a smaller proportion $(\sim 10 \%)$ of the fluxes originates from an area beyond $10 \mathrm{~km}^{2}$ around the tower. The analysis supports the assumption that the measured flux data represent an effective spatial average over most medium-scale topographical landscape elements in this area, including plateaus, slopes, and valleys.

\subsection{Airborne measurements}

For the accurate vertical profiling of VOC mixing ratios from 50 to $3000 \mathrm{~m}$ above the canopy, we employed a Bandeirante aircraft (model EMB 110B1) equipped with the same automated VOC sampler as used for the tower-based SLG measurements. The eight profiles reported here were obtained during the period of 5-17 July 2001, just in advance of the intensive tower-based flux measurements. Five of these profile measurements were made around midday (10:00-12:00 local time, LT), and three profile measurements were conducted in the late afternoon (16:00-18:00 LT). For each of the respective flights a similar flight path and schedule was used. A map showing the footprint area and the typical flight path is given in Fig. 1. After take off at the airport of Manaus and transfer to the K34 tower site, the profile flight schedule consisted of (i) a continuous spiral up from $>50 \mathrm{~m}$ to altitudes of $>3000 \mathrm{~m}$ above canopy, followed by (ii) a stepwise descending pattern with 6 flight legs, one on top of the other, in the vicinity of the K34 tower (Fig. 1). During each flight 2-4 samples were collected within the CBL for MLG flux calculations. A Global Positioning System (GPS) tracked the aircraft's position in longitude, latitude, and altitude.

VOC sample collections were accomplished at constant altitude and aircraft speed along the main wind direction, 
upwind of the K34 tower site. Each of these flight legs allowed for a $15 \mathrm{~min}$ cartridge sampling interval (at flow rates of $200 \mathrm{ml} \mathrm{min}^{-1}$ ). Each flight path covered a length of ca. $65 \mathrm{~km}$ to provide sufficient integration time to spatially average over at least several eddies, in order to obtain representative mean CBL concentration profiles. The automatic VOC sampler for solid sorbent cartridges allowed the collection of two samples simultaneously, and was used (i) for quality assurance samples, using the same type of cartridges and analysis, and (ii) to collect samples on different types of adsorbents that were analysed by GC-FID and GCMS to cross-check identification and quantification of VOC species. Occasionally, canister samples were collected in the middle of each flight leg, with sampling times of a few seconds. These were used as a third backup system specifically for isoprene determination. $\mathrm{CO}_{2}$ and $\mathrm{H}_{2} \mathrm{O}$ mixing ratios were measured by an infrared gas analyzer (Licor 6261) setup according to Lloyd et al. (2002). After take-off, ambient air from outside of the aircraft was continuously drawn through a ca. $5 \mathrm{~m}$ long $1 / 4^{\prime \prime}$ Teflon tube. The inlet end was forward of all engines, and was equipped with a Teflon filter of $2 \mu \mathrm{m}$ pore size that was replaced prior to each flight. To avoid possible ozone interference, an ozone scrubber consisting of multiple plies of $\mathrm{MnO}_{2}$-coated copper mesh (Type TO341FC003, Ansyco, Karlsruhe, Germany) was mounted in the sample line ahead of the VOC sampler.

\subsection{Flux estimation by the mixed layer gradient approach}

The CBL is subdivided into a surface layer (lowest 10\%) and a mixed layer (ML). While transport in the surface layer is dominated by mechanical turbulence provided by the surface friction, transport in the ML is mainly due to convective turbulence, which is thermally driven (Fisch et al., 2004). The top of the CBL is determined in general by a capping inversion in the potential temperature profile. The ML is dominated by convective eddies whose scales are comparable to the depth of the entire CBL. It is considered to be well-mixed, i.e., the mean mixing ratio of a conserved scalar that is emitted from the ground is expected to decrease only gradually with altitude. The observed vertical profiles of VOC mixing ratios were used to estimate fluxes on a landscape scale.

The mixed layer gradient (MLG) technique calculates surface fluxes of passive scalars based on mean mixing ratio differences in the ML. The MLG approach assumes a horizontally homogenous system, implying spatial homogeneity in emissions and vertical mixing of the CBL. Vertical mixing ratio gradients within the mixed layer of any conserved scalar $d C / d z$ are then solely determined by surface and entrainment fluxes, the height of the $\operatorname{CBL}\left(z_{i}\right)$, the convective velocity scale $\left(w^{*}\right)$, and the non-dimensional bottom-up and top-down gradient function (Davis et al., 1994; Patton et al., 2003). The height of the CBL is defined as the height where the potential temperature and other scalar profiles have a maximum of the variance (Stull, 1988). In most cases $z_{i}$ could be estimated as the lowest altitude at which the potential temperature profile showed a persistent change from well mixed to subadiabatic conditions. Where this was not clearly indicated, the profiles of $\mathrm{H}_{2} \mathrm{O}, \mathrm{CO}_{2}$, and other measured trace constituents like $\mathrm{CO}$, ozone, and aerosols were taken into account. The convective velocity scale $\left(w^{*}\right)$ was defined as (Deardorff, 1970)

$w^{*}=\left(\frac{g}{\theta_{0}} \times Q \times z_{i}\right)^{\frac{1}{3}}$

where $g$ is the acceleration of gravity, $\theta_{0}$ is the potential temperature, and $Q$ is the surface virtual heat flux. The potential temperature and the virtual heat flux were derived from EC measurements for the specific time periods of the airborne measurements within the CBL.

Using $w^{*}$, the characteristic timescale $\tau$ for turbulent transport (mixing) within the CBL can be approximated (e.g. Krol et al., 2000; Banta and White, 2003) by:

$\tau=\frac{z_{i}}{w^{*}}$

Entrainment fluxes were estimated from the growth rates of the CBL (between 0.01 and $0.05 \mathrm{~m} \mathrm{~s}^{-1}$ ) and the observed concentration differences across the CBL top. The surface fluxes were obtained by fitting the MLG equation to the measured concentrations within the CBL with a least squares method. For further details see Spirig et al. (2004).

\subsection{Modeling of VOC emission and atmospheric chemistry}

For comparison and interpretation purposes, the biogenic emission and chemical processing of VOCs in the tropical atmosphere have been simulated with a single-column chemistry and climate model (SCM; Ganzeveld et al., 2002; Ganzeveld and Lelieveld, 2004). The SCM has been constrained with the meteorological analysis of the European Centre for Medium range Weather Forecast (ECMWF) model, to simulate a realistic representation of the observed meteorology (Ganzeveld et al., 2006a). VOC emissions were calculated according to Guenther et al. (1995). The simulations represent atmosphere-biosphere exchanges for a forest ecosystem with a LAI of 5, a canopy height of $30 \mathrm{~m}$, a roughness length of $2 \mathrm{~m}$, and VOC and NO emission factors for the Olson (1992) ecosystem class "tropical broadleaf seasonal, with dry or cool season".

The model was nudged towards the observed free tropospheric mixing ratios of a selection of long-lived trace gases, e.g. ozone, $\mathrm{CO}$ and VOCs to mimic advective transport. The soil NO emission flux was calculated using a soil moisture representative for wet season conditions. Because the simulated nocturnal concentrations of isoprene, MVK, and MACR in the model were generally higher than were observed in tropical areas (e.g. Kesselmeier et al., 2000, 2002), the model-simulated nocturnal mixing ratios of these compounds have been forced (e.g., Ganzeveld et al., 2006b) to 
decrease steadily during the night, reaching minimum mixing ratios below $0.2 \mathrm{ppb}$ before sunrise. The reason for the model's misrepresentation of the nocturnal depletion, e.g. from nocturnal removal by turbulent mixing, dry deposition, or residual layer chemistry, needs further investigation.

\section{Results and discussion}

\subsection{Meteorological conditions and VOC mixing ratios}

The LBA-CLAIRE 2001 campaign was carried out in the beginning of the dry season, when the Inter-Tropical Convergence Zone was located at ca. $6^{\circ} \mathrm{N}$, and air flow in the lowest $5 \mathrm{~km}$ of the atmosphere was dominated by easterly trade winds, which transported humid oceanic air masses from the Atlantic over the forests of the Amazon Basin (Silva Dias et al., 2002). Airborne profile measurements were carried out on six days in the period of 05-17 July 2001, and tower-based flux measurements on seven days in the period of 17-25 July 2001. Weather conditions were similar for both periods, mostly dry and sunny, with intermittent cloud patches travelling over the site. The local mean daytime (09:00-18:00 LT) wind direction was predominantly from the east for the tower-based flux measurements, with only a slight shift to the south during the airborne measurements (Fig. 3). Back-trajectories calculated using the HYbrid Single-Particle Lagrangian Integrated Trajectory (HYSPLIT) model showed a consistent flow of air from the East to the measurement site throughout the experimental period. The air parcel back-trajectories for the time frame of the individual flights are shown with the land cover in Fig. 1. The trajectory analysis showed no evidence of air having passed over the nearby city of Manaus, over areas of large-scale deforestation, or over extended areas of open water in rivers or lakes. With vast expanses of pristine forest situated to the east of the K34 tower, this site can be expected to be representative of an undisturbed remote rainforest ecosystem during easterly winds. Previous measurements in the Amazon Basin have shown that radiative cooling at dusk results in the formation of a shallow, decoupled nocturnal boundary layer over the forest, whilst heating of the surface in the morning causes a well mixed CBL to develop at a vertical growth rate of ca. $10 \mathrm{~m} \mathrm{~min}^{-1}$ (Garstang et al., 1988). The CBL heights, deduced from the airborne profile measurements of potential temperature and other trace constituents, ranged between 450 and $1115 \mathrm{~m}$, and were within the typical mixed layer heights that are expected above Amazonian tropical forests (Dias et al., 2002; Fisch et al., 2004).

Isoprene was the dominant biogenic VOC observed in ambient air contributing up to $90 \%$ of the measured species. The mixing ratios of $\alpha$-pinene were an order of magnitude lower, and comprised about half of the detected sum of monoterpene species. The VOC species composition was very similar throughout the boundary layer, when (i) values from the

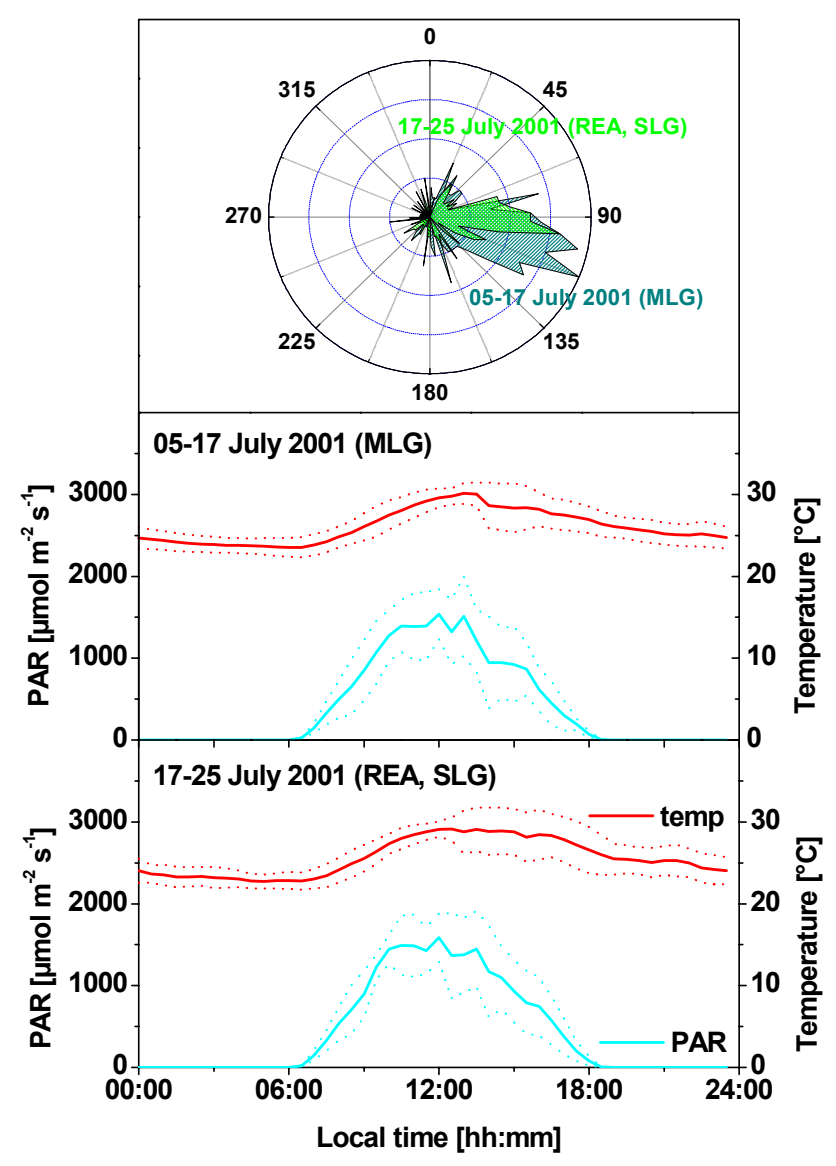

Fig. 3. Comparison of meteorological conditions during the two intensive measurement periods, of 5-17 July 2001 for airborne MLG, versus 17-25 July 2001 for tower-based REA and SLG. Upper panel: frequency distribution of daytime wind directions (09:0018:00 LT); lower panels: ambient temperature and PAR mean values (solid lines) \pm standard deviation (dotted lines).

tower-based measurements in the surface layer versus the data observed within the CBL, and (ii) midday versus afternoon values were compared. Toluene and benzene mixing ratios were relatively low $(\leq 0.1 \mathrm{ppb})$ and did not show distinct vertical profiles, indicative of the absence of human activities or other significant air pollution sources at this remote forest site.

Figure 4 shows a contour plot of a typical diel course of the isoprene and $\alpha$-pinene mixing ratios observed directly above the canopy, which was inferred from surface layer profiles measured simultaneously at four different heights, on an hourly basis. Isoprene and $\alpha$-pinene mixing ratios followed a clear diel pattern as a function of light and temperature (see also Rinne et al., 2002; Kuhn et al., 2002). Mean daytime mixing ratios for isoprene and $\alpha$-pinene reached $3.4 \mathrm{ppb}$ and $0.34 \mathrm{ppb}$ at $51 \mathrm{~m}$ above ground. Maximum isoprene and $\alpha$-pinene values reached $6.6 \mathrm{ppb}$ and $0.6 \mathrm{ppb}$, respectively. Due to intermittent cloud patches travelling over the site in 


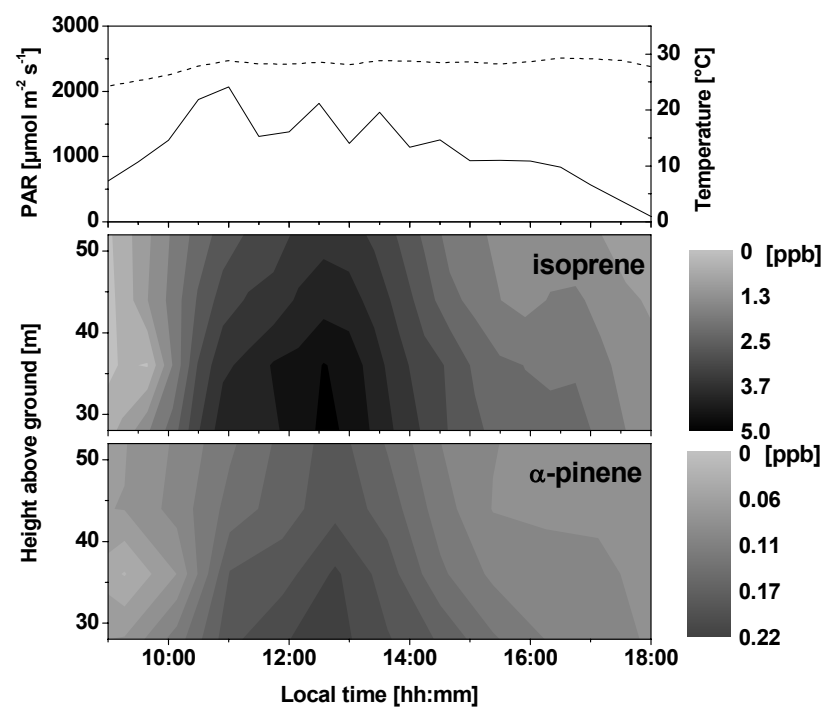

Fig. 4. Above-canopy mixing ratios of isoprene (middle panel) and $\alpha$-pinene (lower panel) measured on 25 July 2001, and respective light intensity (PAR, solid line) and air temperature (dashed line). The contour plots are inferred from VOC gradients measured on an hourly basis simultaneously on four different heights above ground at $51,42.5,35.5$, and $28 \mathrm{~m}$; canopy top was $\sim 30 \mathrm{~m}$.

the afternoon, the maximum mixing ratios were observed as early as midday.

\subsection{Surface fluxes of isoprene and monoterpenes}

\subsubsection{Fluxes derived by SLG and REA}

VOC fluxes were calculated by the SLG approach using the concentration gradient between the two uppermost heights of the tower-based profile measurements. All SLG measurements were accompanied by simultaneous (synchronized in time and sampling period) REA measurements, the latter assumed to have the least degree of uncertainty of all flux methods applied in this study. Figure 5 shows a comparison of the mean diel cycle of isoprene and $\alpha$-pinene fluxes determined by both methods for the whole measurement period. Mean daytime (10:00-15:00 LT) fluxes measured by the REA approach were $2.1 \pm 1.6 \mathrm{mg} \mathrm{C} \mathrm{m}^{-2} \mathrm{~h}^{-1}$ for isoprene, $0.20 \pm 0.18 \mathrm{mg} \mathrm{C} \mathrm{m}^{-2} \mathrm{~h}^{-1}$ for $\alpha$-pinene, and $0.39 \pm 0.43 \mathrm{mg} \mathrm{C} \mathrm{m}^{-2} \mathrm{~h}^{-1}$ for the sum of monoterpenes. With the SLG approach, the respective fluxes were $\quad 3.4 \pm 3.6 \mathrm{mg} \mathrm{C} \mathrm{m}^{-2} \mathrm{~h}^{-1}, \quad 0.20 \pm 0.33 \mathrm{mg} \mathrm{C} \mathrm{m}^{-2} \mathrm{~h}^{-1}$, and $0.38 \pm 0.58 \mathrm{mg} \mathrm{m}^{-2} \mathrm{~h}^{-1}$. The maximum fluxes that were measured with REA were $5.4 \mathrm{mg} \mathrm{C} \mathrm{m}^{-2} \mathrm{~h}^{-1}$ for isoprene (11.3 $\mathrm{mg} \mathrm{C} \mathrm{m}^{-2} \mathrm{~h}^{-1}$ with SLG), $0.89 \mathrm{mg} \mathrm{C} \mathrm{m}^{-2} \mathrm{~h}^{-1}$ for $\alpha$-pinene $\left(1.19 \mathrm{mg} \mathrm{C} \mathrm{m}^{-2} \mathrm{~h}^{-1}\right.$ with $\left.\mathrm{SLG}\right)$, and $1.70 \mathrm{mg} \mathrm{C} \mathrm{m}^{-2} \mathrm{~h}^{-1}$ for the sum of monoterpenes (1.86 $\mathrm{mg} \mathrm{m}^{-2} \mathrm{~h}^{-1}$ with SLG). In general, flux estimates by both approaches were in reasonable agreement.

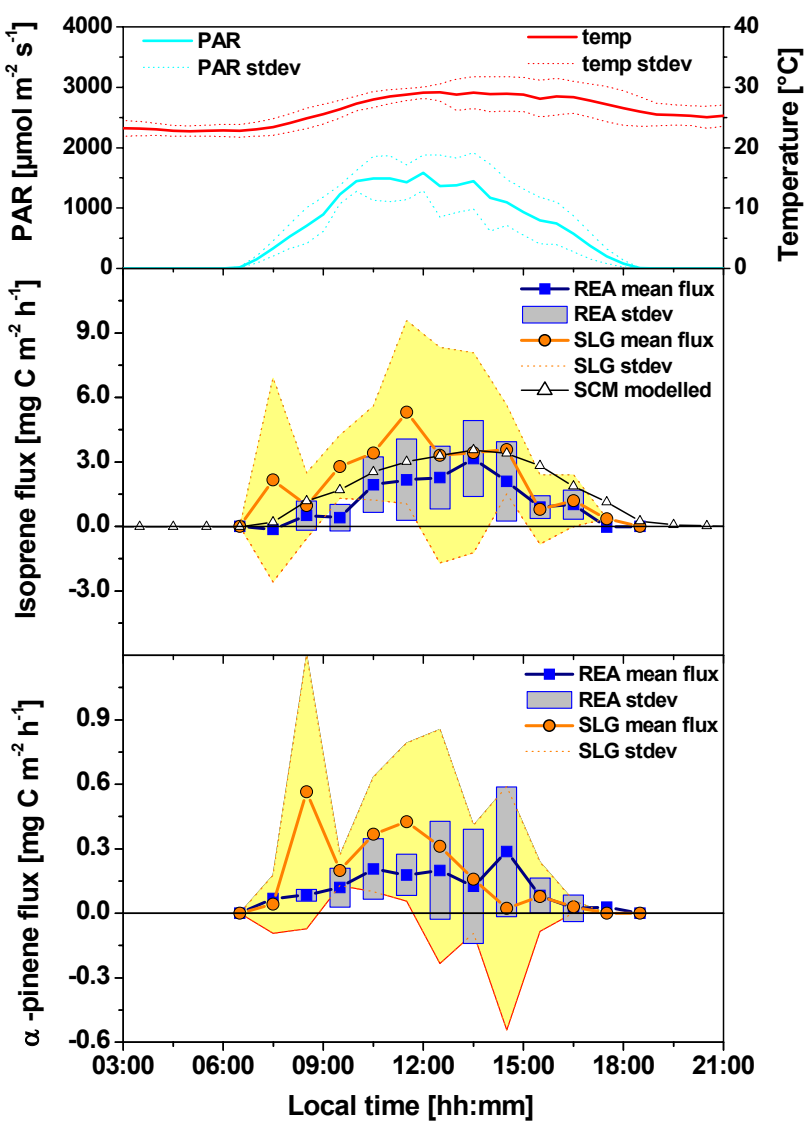

Fig. 5. Hourly mean values of isoprene and $\alpha$-pinene fluxes and environmental conditions for the period 17-25 July $2001 \quad(n=3-$ 8 ). The data points represent arithmetic mean values \pm standard deviation (squares with floating columns for the REA; and circles with shaded area for SLG). The middle panel additionally shows the mean values for the respective time frame predicted by the singlecolumn chemistry and climate model (SCM).

The SLG fluxes exhibited a higher scatter, as expected for the complex terrain of heterogeneous tall vegetation canopies, and exceeded the REA fluxes in most cases (Fig. 5).

The tower-based canopy scale fluxes, with an estimated footprint area of $2-3 \mathrm{~km}^{2}$, are assumed to be representative of the combination of the characteristic local-scale landscape elements in this area, including plateaus, slopes, and valleys. The observed range of VOC flux values are consistent with those reported previously for remote tropical Amazon forest ecosystems (Table 1), and are in accordance with fluxes used for this region in global model estimates (Guenther et al., 1995). The mean daily integrated emission determined by REA sums up to $21 \mathrm{mg} \mathrm{C} \mathrm{m}^{-2} \mathrm{~d}^{-1}$ for isoprene and $3 \mathrm{mg} \mathrm{C} \mathrm{m}^{-2} \mathrm{~d}^{-1}$ for the sum of monoterpenes. Measured surface fluxes of biogenic VOC were roughly proportional to mixing ratios within the boundary layer, as expected for compounds whose atmospheric lifetime is substantially less than 1 day. 
Table 1. VOC fluxes in the Amazon tropical rain forest: estimates and direct measurements reported in literature and mean values from 3 methodologies used in this study. All numbers are based on carbon. Note that flux estimates of Jacob and Wofsy (1988), Zimmerman et al. (1988), and Davis et al. (1994) were derived from the same observational data base.

\begin{tabular}{|c|c|c|c|c|c|c|}
\hline study & $\begin{array}{l}\text { isoprene } \\
{\left[\mathrm{mg} \mathrm{C} \mathrm{m}^{-2} \mathrm{~h}^{-1}\right]}\end{array}$ & $\begin{array}{l}\alpha \text {-pinene } \\
{\left[\mathrm{mg} \mathrm{C} \mathrm{m}^{-2} \mathrm{~h}^{-1}\right]}\end{array}$ & $\begin{array}{l}\text { sum of monoterpenes } \\
{\left[\mathrm{mg} \mathrm{C} \mathrm{m}^{-2} \mathrm{~h}^{-1}\right]}\end{array}$ & site & technical approach & comments \\
\hline Jacob and Wofsy (1988) & 2.44 (max. $\sim 6$ ) & & & $\begin{array}{l}\text { ABLE } 2 \text { A campaign, } \\
\text { Duke forest reserve } \\
10 \mathrm{~km} \text { north of Manaus, Brazil }\end{array}$ & $\begin{array}{l}\text { one-dimensional dynamical chemistry } \\
\text { model on vertical profiles within } \mathrm{CBL}\end{array}$ & mean daytime flux (08:00-18:00 LT) \\
\hline Zimmerman et al. (1988) & 2.73 & 0.11 & 0.24 & $\begin{array}{l}\text { ABLE } 2 \text { A campaign, } \\
\text { Duke forest reserve } \\
10 \mathrm{~km} \text { north of Manaus, Brazil }\end{array}$ & $\begin{array}{l}\text { Mass Budget } \\
\text { from vertical profiles within CBL }\end{array}$ & mean daytime flux (08:00-16:00 LT) \\
\hline Davis et al. (1994) & $3.63 \pm 1.4$ & & & $\begin{array}{l}\text { ABLE } 2 \text { A campaign, } \\
\text { Duke forest reserve }\end{array}$ & $\begin{array}{l}\text { Mixed Layer Gradient } \\
\text { from vertical profiles within CBL }\end{array}$ & mean daytime flux (08:00-15:00 LT) \\
\hline Helmig et al. (1998) & $2.64-7.24$ & $0.11-0.33$ & $0.19-0.45$ & remote Amazon forest, Peru & $\begin{array}{l}\text { Mixed Layer Gradient and Mass Budget } \\
\text { from vertical profiles within CBL }\end{array}$ & mean daytime flux $(10: 00-18: 00 \mathrm{LT})$ \\
\hline Stefani et al. (2000) & 1.1 & & 0.20 & K34 tower $60 \mathrm{~km}$ north of Manaus, Brazil & Relaxed Eddy Accumulation & $30^{\circ} \mathrm{C}, 1100 \mu \mathrm{mol} \mathrm{m}^{-2} \mathrm{~s}^{-1}$ PAR \\
\hline Rinne et al. (2002) & 2.12 & 0.23 & & Floresta Nacional do Tapajos, Para, Brazil & $\begin{array}{l}\text { Eddy Covariance (isoprene) } \\
\text { Disjunct True Eddy Accumulation (pinene) }\end{array}$ & $30^{\circ} \mathrm{C}, 1000 \mu \mathrm{mol} \mathrm{m}^{-2} \mathrm{~s}^{-1} \mathrm{PAR}$ \\
\hline Geron et al. (2002) & 2.2 & & & La Selva, Heredia, Costa Rica & Relaxed Eddy Accumulation & $\begin{array}{l}28^{\circ}, 1100 \mu \mathrm{mol} \mathrm{m}^{-2} \mathrm{~s}^{-1} \text { PAR } \\
\text { partly cloudy conditions }\end{array}$ \\
\hline $\begin{array}{l}\text { Karl et al. (2004) } \\
\text { Greenberg et al. (2004) }\end{array}$ & $\begin{array}{l}1.19(\max .2 .56) \\
\max .1 .94\end{array}$ & $\max .0 .08$ & $\begin{array}{l}0.09(\max .0 .33) \\
\max 0.16\end{array}$ & $\begin{array}{l}\text { La Selva, Heredia, Costa Rica } \\
\text { FLONA Tapajo's, Brazil }\end{array}$ & $\begin{array}{l}\text { Disjunct Eddy Covariance } \\
\text { one-dimensional chemistry model }\end{array}$ & $\begin{array}{l}\text { mean daytime flux } \\
\text { maximal flux }\end{array}$ \\
\hline & $\begin{array}{l}\max .4 .68 \\
\max .865\end{array}$ & $\begin{array}{l}\max .0 .11 \\
\max .0 .16\end{array}$ & $\max .0 .20$ & $\begin{array}{l}\text { Balbina, } 150 \mathrm{~km} \text { north of Manaus, Brazil } \\
\text { Reserva Biologica do Jaru, Rondonia, Brazil }\end{array}$ & on vertical profiles within CBL & \\
\hline this study & $\begin{array}{l}2.1 \pm 1.6(\max .5 .4) \\
3.4 \pm 3.6(\max .11 .3)\end{array}$ & $\begin{array}{l}0.20 \pm 0.18(\max .0 .89) \\
0.20 \pm 0.33(\max .1 .19)\end{array}$ & $\begin{array}{l}0.39 \pm 0.43(\max .1 .70) \\
0.38 \pm 0.58(\max .1 .86)\end{array}$ & K34 tower $60 \mathrm{~km}$ north of Manaus, Brazil & $\begin{array}{l}\text { Relaxed Eddy Accumulation } \\
\text { Surface Layer Gradient }\end{array}$ & $\begin{array}{l}\text { mean daytime flux }(10: 00-15: 00 \mathrm{LT}) \\
\text { mean daytime flux (10:00-15:00 LT) }\end{array}$ \\
\hline
\end{tabular}

Like isoprene, the monoterpenes were also emitted by the tropical vegetation in a light-dependent manner. In agreement with previous studies, there is now increasing evidence that light dependence of monoterpene emissions can be generalized for tropical forests (Rinne et al., 2002; Kuhn et al., 2002; 2004a; Karl et al., 2004), as well as for deciduous tree species in temperate ecosystems (Staudt and Seufert, 1995; Ciccioli et al., 1997; Kesselmeier et al., 1996; Spirig et al., 2005; Dindorf et al., 2006). For anthropogenic VOC mainly deposition was observed. In particular average daily fluxes of $-0.21,-0.02$ and less than $-0.01 \mathrm{mg} \mathrm{C} \mathrm{m}^{-2} \mathrm{~h}^{-1}$ were measured for benzene, toluene and $\mathrm{CCl} 4$ during this campaign. These values are similar to those reported previously for the same site (Andreae et al., 2002).

\subsubsection{Comparison with modeled fluxes}

The isoprene surface flux for the measurement region has been simulated with the single-column chemistry and climate model (SCM), which was constrained with the analyzed meteorology from the ECMWF data base as described in Sect. 2.6. The diel course of mean modelled fluxes of all measurement days were in a range between those calculated by REA and SLG (Fig. 5, middle panel), and hence showed good agreement with observations. The evaluation indicates that the implementation of the Guenther et al. (1995) algorithm in the SCM reproduced the observed fluxes reasonably well. As shown in Fig. 6, on sunny days the model simulated maximum fluxes comparable to the REA fluxes (e.g., 19 and 20 July), but did not capture the observed diel variability during partly cloudy days, with intermittent cloud patches travelling over the site (e.g. 17 and 19 July). This difference is likely due to the fact that average model grid data of PAR do not ideally reflect the highly variable light conditions at the measurement site, as the treatment of average

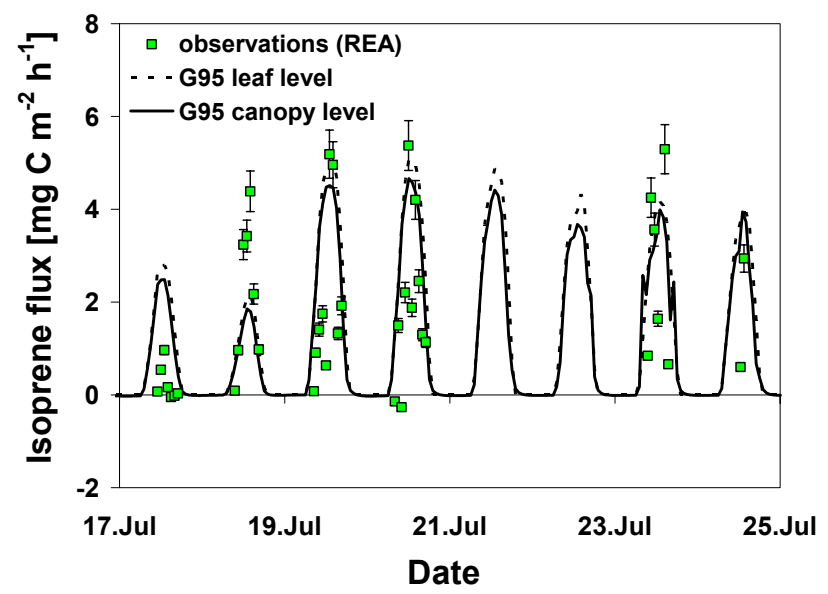

Fig. 6. Comparison of isoprene fluxes observed by REA (squares), and modelled with a single-column chemistry and climate model (SCM), with implementation of the Guenther et al. (1995) algorithm (G95), and constrained with the analyzed meteorology of the European Centre for Medium range Weather Forecast (ECMWF) model. The dotted line represents fluxes based on the leaf surface, while the solid line shows the fluxes calculated for the canopy level, including within-canopy interactions of gas phase chemistry, soil uptake, and turbulent mixing.

cloud cover in model grids does not capture any subgrid scale variability of PAR. The influence of the non-linearity in the light-dependence of isoprene emissions on this issue is currently under further evaluation.

It has to be considered that the surface flux measured by micrometeorological techniques at the canopy level likely differs from the primary plant emission usually implemented in the models. The difference depends on the degree to which isoprene, that is emitted from leaves, is oxidized while still 


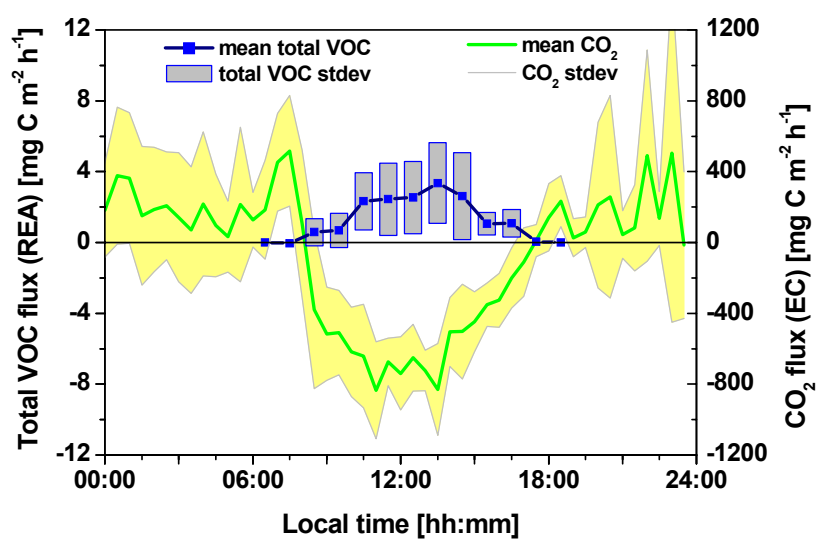

Fig. 7. Mean values of total VOC fluxes (isoprene and monoterpenes) measured by REA, and $\mathrm{CO}_{2}$ fluxes calculated by eddy correlation (EC) during the period of 17-25 July 2001. The data points represent arithmetic mean values \pm standard deviation (squares with floating columns for VOC-REA; and green line with shaded area for $\mathrm{CO}_{2}$-EC).

in the canopy air space, prior to being ventilated to the wellmixed atmosphere. The simulated difference between isoprene fluxes modelled at the leaf level and modelled at the canopy scale is explicitly shown in Fig. 6. This difference, on the order of $10 \%$, reflects the influence of within-canopy interactions of gas-phase chemistry, soil uptake (Cleveland, 1997), and turbulent mixing in the SCM model. This is in agreement with recent results by Stroud et al. (2005), who suggested a 5 to $10 \%$ reduction of the isoprene emission rate due to chemical loss within the canopy. It is also similar to results of Karl et al. (2004), who inferred from the ratio (MVK+MACR)/isoprene in in-canopy air, that less than $10 \%$ of isoprene is oxidized within a tropical forest canopy. All of this leads to the conclusion that in (and directly above) a tropical forest canopy the transport time scale is considerably faster than the time scale for chemical loss of isoprene, and that the bias of in-canopy atmospheric chemistry for the overall isoprene (and $\alpha$-pinene) flux measurements is relatively small, i.e., within the uncertainty of the micrometeorological flux measurement approaches.

Even though the flux values of isoprene are reasonably well reproduced by the SCM, the comparison of the simulated and observed mixing ratios showed a significant overestimation for isoprene, as is commonly the case in atmospheric chemistry models (Poisson et al., 2000; Bey et al., 2001; von Kuhlmann et al., 2004). The simulated maximum daytime surface layer mixing ratios are as large as $12 \mathrm{ppb}$, whereas the maximum observed mixing ratios do not exceed $6.6 \mathrm{ppb}$. A potential explanation for the general overestimation of isoprene may be found in an underestimation of the modelled chemical destruction of isoprene, associated with too low $\mathrm{OH}$ radical concentrations simulated by current models, as will be discussed in Sect. 3.3.

\subsubsection{Implications for the local carbon budget}

The $\mathrm{CO}_{2}$ sink strength of the Amazon rain forest is of special interest for regional as well as global carbon and greenhouse gas budget studies. Biogenic VOCs do offset the net ecosystem carbon fluxes, and hence constitute an integral component of the global carbon cycle (Guenther et al., 2002; Kesselmeier et al., 2002). The observed VOC emission rates were related to the concurrent $\mathrm{CO}_{2}$ net exchange of the forest, in order to estimate the contribution of VOCs in the local ecosystem carbon cycle during LBA-CLAIRE 2001.

Figure 7 shows hourly mean fluxes of the sum of measured VOCs for the period of 17-25 July 2001 with the corresponding direct measurements of $\mathrm{CO}_{2}$ fluxes by tower-based EC. Daytime net $\mathrm{CO}_{2}$ influxes during the period of maximal net photosynthesis were as high as $20 \mu \mathrm{mol} \mathrm{m}^{-2} \mathrm{~s}^{-1}$. Nocturnal net $\mathrm{CO}_{2}$ effluxes (including autotrophic and heterotrophic respiration) were typically in the range between $5-10 \mu \mathrm{mol} \mathrm{m}^{-2} \mathrm{~s}^{-1}$, resulting in a mean daily $(24 \mathrm{~h})$ integrated net $\mathrm{CO}_{2}$ sink strength of $2017 \mathrm{mg} \mathrm{C} \mathrm{m}^{-2} \mathrm{~d}^{-1}$ for the local net ecosystem exchange (NEE). Relative to these results of the $\mathrm{CO}_{2}-\mathrm{EC}$, the daily integrated amount of carbon re-emitted by VOCs as measured by REA $\left(24 \mathrm{mg} \mathrm{C} \mathrm{m}^{-2} \mathrm{~d}^{-1}\right.$ for isoprene plus monoterpenes) was $1.2 \%$ ( $0.6 \%$ during the photoperiod), which is somewhat lower than the range (2.7$3.7 \%$ ) derived from eddy covariance measurements of VOCs and $\mathrm{CO}_{2}$ fluxes for a low land tropical wet forest site reported by Karl et al. (2004).

Yet, as is extensively discussed in the literature (Culf et al., 1999; Baldocchi et al., 2000, 2003; Martens et al., 2004; Kruijt et al., 2004; Ometto et al., 2005), the EC- $\mathrm{CO}_{2}$ measurements during nighttime have to be used with caution, as they are subject to potential systematic errors at low wind speeds, and the daily integrated numbers of EC may be overestimated, especially in spatially complex terrain. The uncertainties stem from difficulties related to (i) night time calm conditions, when respired $\mathrm{CO}_{2}$ tends to accumulate within the forest canopy and intermittent updraft events transfer it to the atmosphere in a complex spatial pattern not consistently caught by the flux tower sensors (Staebler and Fitzjarrald, 2004), and (ii) an irregular topography, where lateral $\mathrm{CO}_{2}$ advection to lower positions on the landscape can result in $\mathrm{CO}_{2}$ draining out from the eddy covariance tower footprint (Araújo et al., 2002). Considering the methodological uncertainties and applying different methods of data treatment, Araújo et al. (2002) gave a relatively wide range for the annual NEE of $1-8 \mathrm{tCha}^{-1} \mathrm{a}^{-1}$ estimated from a one year record of EC data for the same measurement site. A linear down-scaling to daily values results in a range of 270 $2200 \mathrm{mg} \mathrm{C} \mathrm{m}^{-2} \mathrm{~d}^{-1}$, which suggests the above EC result of $2017 \mathrm{mg} \mathrm{C} \mathrm{m}^{-2} \mathrm{~d}^{-1}$ as being close to the upper limit. Relative to the lower range limit, carbon re-emitted as isoprene and monoterpenes would account for a considerable fraction of up to $9 \%$. 
Table 2. Carbon re-emitted as VOC compared to different $\mathrm{CO}_{2}$ budget estimates that were carried out during the intensive LBA-CLAIRE campaign. Numbers are based on daily integrated mean fluxes of $21 \mathrm{mg} \mathrm{C} \mathrm{m}^{-2} \mathrm{~d}^{-1}$ for isoprene and $3 \mathrm{mg} \mathrm{C} \mathrm{m}^{-2} \mathrm{~d}^{-1}$ for the sum of monoterpenes derived by REA measurements.

\begin{tabular}{lcc}
\hline $\begin{array}{l}\text { Method (base/footprint) (reference) } \\
\text { time period }\end{array}$ & $\begin{array}{c}\mathrm{CO}_{2} \text { exchange } \\
{\left[\mathrm{mg} \mathrm{C} \mathrm{m}^{-2} \mathrm{~d}^{-1}\right]}\end{array}$ & $\begin{array}{c}\mathrm{C}_{\mathrm{VOC}} / \mathrm{C}_{\mathrm{CO}_{2}} \\
{[\%]}\end{array}$ \\
\hline $\begin{array}{l}\text { Eddy Correlation (tower/local) (this work) } \\
12 \text { h daytime }\end{array}$ & -3947 & 0.6 \\
$\begin{array}{l}\text { Eddy Correlation (tower/local) (this work) } \\
24 \mathrm{~h}\end{array}$ & -2017 & 1.2 \\
$\begin{array}{l}\text { Inverse Lagrangian Dispersion Model (tower/local) (Simon et al., 2005) } \\
24 \mathrm{~h}\end{array}$ & -384 & 6.3 \\
$\begin{array}{l}\text { Boundary Layer Mass Budget (airborne/regional) (Lloyd et al., 2007) } \\
24 \mathrm{~h}\end{array}$ & $\leq-300$ & $\geq 8.0$ \\
\hline
\end{tabular}

Two alternative methods to estimate the $\mathrm{CO}_{2}$ sequestration rate for the $\mathrm{K} 34$ site, measured at this specific site during the time period of the LBA-CLAIRE campaign, may help to reduce the high uncertainty (Table 2). Using an inverse Lagrangian dispersion model for ${ }^{222} \mathrm{Rn}, \mathrm{H}_{2} \mathrm{O}$ and $\mathrm{CO}_{2}$, Simon et al. (2005) predicted a low daily net carbon sink of only $384 \mathrm{mg} \mathrm{C} \mathrm{m}^{-2} \mathrm{~d}^{-1}$ for a four-day period (16-20 July 2001). As a second independent method, midday and afternoon vertical profiles of $\mathrm{CO}_{2}$ within and above the CBL were measured in parallel to the airborne VOC data, and used to calculate concurrent regional $\mathrm{CO}_{2}$ fluxes by application of a mass budget model (Lloyd et al., 2007). The authors state that on a regional scale the $\mathrm{K} 34$ region was even a small source of $\mathrm{CO}_{2}$ rather than a sink during the period of LBA-CLAIRE. Within the associated uncertainties of this mass budget approach, the authors point out that a modest carbon sink as low as $300 \mathrm{mg} \mathrm{C} \mathrm{m}^{-2} \mathrm{~d}^{-1}$ can not be excluded. Both alternative methods (Simon et al., 2005; Lloyd et al., 2007) revealed daytime $\mathrm{CO}_{2}$ fluxes quite similar to the eddy covariance method, but suggested significantly higher nighttime net $\mathrm{CO}_{2}$ release, and hence lower net $\mathrm{CO}_{2}$ exchange rates on the $24 \mathrm{~h}$ basis, all leading to the conclusion that the contribution of VOC carbon fluxes in the regional carbon budget is in a range of $\geq 6 \%$ (Table 2 ).

Using a process-based biogeochemical model of terrestrial ecosystems, Tian et al. (1998) reported an average annual net primary production (NPP) for the entire Amazon Basin of $\sim 5000 \mathrm{Tg} \mathrm{Ca}^{-1}$, nearly compensated by heterotrophic respiration of $\sim 4800 \mathrm{Tg} \mathrm{Ca}^{-1}$, ultimately resulting in an average annual net ecosystem production (NEP) of only $200 \mathrm{Tg} \mathrm{Ca}^{-1}$ in the time period between 1980 and 1995. These results were supported by Botta et al. (2002) for the period of 19351995 using a similar approach. Both studies indicated that the Amazonian carbon budget is going through a sequence of neutral, net source, to net sink in response to climate variability (emission up to $200 \mathrm{Tg} \mathrm{Ca}^{-1}$ and uptake up to $700 \mathrm{Tg} \mathrm{Ca}^{-1}$ ). Unfortunately there are very scarce real mea- surements on the seasonal variations of VOC emissions in the Amazon in literature (Kuhn et al., 2004a, b). Extrapolation of the integrated mean daily totals of emissions observed by REA (SLG), assuming similar conditions and a total forested area of $68.9 \times 10^{5} \mathrm{~km}^{2}$ in the Amazon (Botta et al., 2002), the source strength sums up to 35.8 (68.6) $\mathrm{Tg} \mathrm{Ca}^{-1}$ for isoprene and $5.9(8.4) \mathrm{Tg} \mathrm{Ca}^{-1}$ for the sum of monoterpenes, which together comprises about $21 \%$ (39\%) of the long-term mean modelled $\mathrm{CO}_{2}$ sink. Although part of the atmospheric degradation products are deposited by dry or wet deposition, or form secondary organic aerosols (Claeys et al., 2004), the atmospheric fate of almost half of the VOC carbon is estimated to end in $\mathrm{CO}_{2}$ (Kuhlmann, 2001; Poisson et al., 2000; Goldstein and Galbally, 2007). Apart from the VOC species investigated here, further perturbation of the tropical carbon budget may be derived from other organic compounds, most prominently methanol (Galbally et al., 2002) and methane. Besides flooded areas and cattle-breeding, which are currently accounted for with high uncertainties, recent investigations revealed that methane can also be emitted directly from plants in considerable amounts (Keppler et al., 2006; Do Carmo et al., 2006).

\subsection{VOC profiles in the convective boundary layer}

\subsubsection{Airborne measurements}

During the period of 5-21 July 2001, a total of eight VOC profiles between 50 and $3000 \mathrm{~m}$ above canopy level were obtained by airborne measurements. Table 3 gives an overview of all VOC measurements analyzed by GC-FID. The mean profiles of isoprene and $\alpha$-pinene are plotted in Fig. 8. Isoprene and $\alpha$-pinene showed similar characteristics, both declining strongly with altitude, ranging from $4.7 \mathrm{ppb}$ for isoprene and $0.23 \mathrm{ppb}$ for $\alpha$-pinene to below detection limit for both compounds above the CBL. The deviation from the mean values shown in Fig. 8 is attributable to the dayto-day variability in meteorological conditions, rather than 
Table 3. Observed VOC mixing ratios, calculated fluxes and supplementary data from the airborne measurements used for the MLG flux calculations. For flights A, B, C, quality assurance (backup) samples were collected. The convective velocity scales and estimated CBL heights are given for the mean time of the flights within the CBL. Isoprene and $\alpha$-pinene were chemistry adjusted according to Eq. (7). VOC fluxes are given for chemistry adjusted mixing ratios.

\begin{tabular}{|c|c|c|c|c|c|c|c|c|c|c|c|c|c|c|}
\hline $\begin{array}{l}\text { flight } \\
\text { no. } \\
\text { [\#] }\end{array}$ & $\begin{array}{l}\text { date } \\
\text { [dd.mm.yy] }\end{array}$ & $\begin{array}{l}\mathrm{CBL} \\
\text { height } \\
\left(z_{i}\right)[\mathrm{m}]\end{array}$ & $\begin{array}{l}\text { convective } \\
\text { velocity } \\
\text { scale } \\
\left(w^{*}\right) \\
{\left[\mathrm{m} \mathrm{s}^{-1}\right]}\end{array}$ & $\begin{array}{l}\text { sample } \\
\text { time } \\
\text { (LT) } \\
\text { [hh:mm] }\end{array}$ & $\begin{array}{l}\text { sample } \\
\text { height } \\
{[\mathrm{m}]}\end{array}$ & $\begin{array}{l}\text { isoprene } \\
\text { observed } \\
\text { [ppb] }\end{array}$ & $\begin{array}{l}\text { MVK } \\
\text { observed } \\
\text { [ppb] }\end{array}$ & $\begin{array}{l}\text { MACR } \\
\text { observed } \\
{[\mathrm{ppb}]}\end{array}$ & $\begin{array}{l}\alpha \text {-pinene } \\
\text { observed } \\
{[\mathrm{ppb}]}\end{array}$ & $\begin{array}{l}\text { sum of } \\
\text { monoter- } \\
\text { penes } \\
\text { observed } \\
\text { [ppb] }\end{array}$ & $\begin{array}{l}\text { isoprene } \\
\text { chemis- } \\
\text { try } \\
\text { adjusted } \\
\text { [ppb] }\end{array}$ & $\begin{array}{l}\alpha- \\
\text { pinene } \\
\text { chemis- } \\
\text { try } \\
\text { adjusted } \\
\text { [ppb] }\end{array}$ & $\begin{array}{l}\text { isoprene flux } \\
\text { adjusted } \\
{\left[\mathrm{mg} \mathrm{Cm}^{-2} \mathrm{~h}^{-1}\right]}\end{array}$ & $\begin{array}{l}\alpha \text {-pinene flux } \\
\text { adjusted } \\
{\left[\mathrm{mg} \mathrm{C} \mathrm{m}^{-2} \mathrm{~h}^{-1}\right]}\end{array}$ \\
\hline \multirow[t]{12}{*}{ A } & \multirow[t]{12}{*}{05.07 .01} & \multirow[t]{12}{*}{850} & \multirow[t]{12}{*}{1.52} & $10: 56$ & $4345 \pm 07$ & -0.06 & 0.02 & -0.10 & 0.00 & -0.01 & & & \multirow[t]{12}{*}{13.79} & \multirow[t]{12}{*}{1.05} \\
\hline & & & & $10: 56$ & $4345 \pm 07$ & -0.01 & 0.37 & 0.06 & 0.01 & 0.02 & & & & \\
\hline & & & & $11: 20$ & $2694 \pm 10$ & -0.07 & 0.00 & -0.14 & 0.00 & 0.00 & & & & \\
\hline & & & & $11: 20$ & $2694 \pm 10$ & 0.02 & 0.03 & 0.04 & 0.00 & -0.02 & & & & \\
\hline & & & & $11: 37$ & $2041 \pm 04$ & 0.15 & 0.13 & 0.06 & 0.00 & 0.06 & & & & \\
\hline & & & & $11: 37$ & $2041 \pm 04$ & 0.10 & 0.18 & 0.05 & 0.00 & -0.02 & & & & \\
\hline & & & & $12: 03$ & $774 \pm 33$ & 0.34 & 0.07 & 0.01 & 0.05 & 0.06 & 1.12 & 0.07 & & \\
\hline & & & & $12: 03$ & $774 \pm 33$ & 0.62 & 0.27 & 0.22 & 0.03 & 0.05 & 1.40 & 0.05 & & \\
\hline & & & & $12: 23$ & $301 \pm 09$ & 2.02 & 0.53 & 0.33 & 0.11 & 0.23 & 2.34 & 0.12 & & \\
\hline & & & & $12: 23$ & $301 \pm 09$ & 1.87 & 0.22 & 0.08 & 0.10 & 0.17 & 2.20 & 0.11 & & \\
\hline & & & & $12: 41$ & $87 \pm 14$ & 3.32 & 0.62 & 0.25 & 0.14 & 0.25 & 3.42 & 0.14 & & \\
\hline & & & & $12: 41$ & $87 \pm 14$ & 2.98 & 0.38 & 0.22 & 0.14 & 0.23 & 3.08 & 0.14 & & \\
\hline \multirow[t]{8}{*}{ B } & \multirow[t]{8}{*}{07.07 .01} & \multirow[t]{8}{*}{450} & \multirow[t]{8}{*}{1.25} & $10: 33$ & $2737 \pm 13$ & 0.04 & 0.28 & 0.06 & 0.00 & 0.06 & & & \multirow[t]{8}{*}{7.23} & 0.79 \\
\hline & & & & $10: 33$ & $2737 \pm 13$ & -0.09 & 0.34 & 0.13 & -0.02 & -0.03 & & & & \\
\hline & & & & $10: 48$ & $2100 \pm 02$ & -0.08 & 0.35 & -0.08 & 0.00 & -0.04 & & & & \\
\hline & & & & $10: 48$ & $2100 \pm 02$ & -0.13 & 0.09 & -0.02 & 0.00 & 0.00 & & & & \\
\hline & & & & $11: 10$ & $477 \pm 15$ & 1.14 & 0.82 & 0.37 & 0.06 & 0.11 & & & & \\
\hline & & & & $11: 10$ & $477 \pm 15$ & 1.18 & 0.50 & 0.23 & 0.23 & 0.41 & & & & \\
\hline & & & & $11: 23$ & $164 \pm 08$ & 1.56 & 0.76 & 0.42 & 0.09 & 0.17 & 1.70 & 0.10 & & \\
\hline & & & & $11: 37$ & $74 \pm 20$ & 2.07 & 0.68 & 0.55 & 0.12 & 0.22 & 2.14 & 0.12 & & \\
\hline $\mathrm{C}$ & 08.07.01 & 400 & 1.26 & 09:54 & $2732 \pm 05$ & -0.06 & -0.06 & -0.05 & 0.00 & 0.00 & & & 1.89 & -0.13 \\
\hline & & & & $09: 54$ & $2732 \pm 05$ & 0.08 & -0.03 & -0.03 & 0.00 & -0.01 & & & & \\
\hline & & & & $10: 12$ & $2105 \pm 03$ & -0.03 & 0.00 & -0.05 & 0.02 & 0.01 & & & & \\
\hline & & & & $10: 12$ & $2105 \pm 03$ & -0.03 & 0.03 & 0.05 & -0.01 & -0.02 & & & & \\
\hline & & & & $10: 35$ & $1442 \pm 03$ & 0.07 & 0.21 & 0.14 & 0.01 & 0.03 & & & & \\
\hline & & & & $10: 35$ & $1442 \pm 03$ & -0.02 & 0.05 & 0.02 & 0.00 & -0.01 & & & & \\
\hline & & & & $10: 55$ & $813 \pm 02$ & 0.12 & 0.22 & 0.20 & 0.01 & 0.02 & & & & \\
\hline & & & & $10: 55$ & $813 \pm 02$ & 0.01 & 0.19 & 0.22 & 0.01 & 0.01 & & & & \\
\hline & & & & $11: 16$ & $323 \pm 04$ & 1.12 & 0.40 & 0.36 & 0.10 & 0.21 & 1.39 & 0.11 & & \\
\hline & & & & $11: 16$ & $323 \pm 04$ & 1.28 & 0.41 & 0.34 & 0.11 & 0.17 & 1.56 & 0.13 & & \\
\hline & & & & $11: 35$ & $62 \pm 22$ & 1.90 & 0.70 & 0.58 & 0.12 & 0.20 & 1.95 & 0.12 & & \\
\hline & & & & $11: 35$ & $62 \pm 22$ & 1.65 & 0.48 & 0.34 & 0.12 & 0.20 & 1.69 & 0.12 & & \\
\hline $\mathrm{D}$ & 10.07 .01 & 1115 & 0.80 & $16: 02$ & $1170 \pm 03$ & 1.56 & 0.49 & 0.17 & 0.09 & 0.17 & & & -2.60 & -0.06 \\
\hline & & & & $17: 06$ & $805 \pm 04$ & 3.81 & 0.49 & 0.25 & 0.16 & 0.25 & 5.84 & 0.21 & & \\
\hline & & & & $17: 20$ & $317 \pm 02$ & 3.72 & 0.55 & 0.37 & 0.11 & 0.16 & 4.67 & 0.13 & & \\
\hline & & & & $17: 32$ & $69 \pm 12$ & 4.73 & 0.98 & 0.47 & 0.19 & 0.36 & 4.96 & 0.20 & & \\
\hline E & 11.07 .01 & 550 & 1.49 & $10: 05$ & $2111 \pm 05$ & - & - & - & - & - & & & 5.95 & 0.60 \\
\hline & & & & $10: 24$ & $1453 \pm 05$ & 0.00 & 0.31 & 0.01 & -0.01 & 0.00 & & & & \\
\hline & & & & $10: 47$ & $825 \pm 04$ & 1.92 & 0.51 & 0.30 & 0.09 & 0.18 & & & & \\
\hline & & & & 11:05 & $319 \pm 07$ & 2.50 & 0.69 & 0.37 & 0.10 & 0.18 & 2.97 & 0.11 & & \\
\hline & & & & $11: 23$ & $94 \pm 06$ & 3.52 & 1.05 & 0.50 & 0.13 & 0.30 & 3.66 & 0.13 & & \\
\hline & & & & $11: 41$ & $45 \pm 17$ & 4.11 & 0.64 & 0.35 & 0.15 & 0.25 & 4.18 & 0.15 & & \\
\hline F & 11.07 .01 & 800 & 0.65 & $16: 08$ & $2124 \pm 06$ & 0.33 & 0.03 & -0.03 & 0.01 & 0.00 & & & 0.09 & 0.24 \\
\hline & & & & $16: 27$ & $1473 \pm 03$ & 0.57 & 0.19 & 0.04 & 0.01 & 0.00 & & & & \\
\hline & & & & $16: 46$ & $807 \pm 02$ & 1.92 & 0.67 & 0.31 & 0.06 & 0.17 & & & & \\
\hline & & & & $17: 04$ & $347 \pm 03$ & 2.07 & 1.63 & 1.04 & 0.06 & 0.15 & 2.77 & 0.08 & & \\
\hline & & & & $17: 21$ & $95 \pm 04$ & 2.56 & 0.53 & 0.31 & 0.10 & 0.18 & 2.77 & 0.10 & & \\
\hline & & & & $17: 39$ & $71 \pm 25$ & 2.72 & 0.42 & 0.21 & 0.10 & 0.17 & 2.89 & 0.11 & & \\
\hline G & 17.07 .01 & 450 & 1.03 & $10: 09$ & $2716 \pm 03$ & 0.03 & 0.06 & 0.10 & 0.03 & 0.02 & & & 2.41 & 0.56 \\
\hline & & & & $10: 25$ & $2080 \pm 21$ & 0.18 & 0.17 & 0.05 & 0.00 & 0.08 & & & & \\
\hline & & & & $10: 40$ & $1439 \pm 04$ & 0.02 & 0.14 & 0.09 & 0.04 & 0.03 & & & & \\
\hline & & & & $10: 56$ & $447 \pm 22$ & 0.74 & 0.09 & 0.18 & 0.06 & 0.09 & 1.19 & 0.08 & & \\
\hline & & & & 11:09 & $169 \pm 03$ & 1.04 & 0.14 & 0.12 & 0.13 & 0.19 & 1.23 & 0.14 & & \\
\hline & & & & $11: 22$ & $56 \pm 14$ & 2.09 & 0.21 & 0.05 & 0.14 & 0.22 & 2.15 & 0.15 & & \\
\hline $\mathrm{H}$ & 17.07 .01 & 850 & 0.76 & $16: 01$ & $2734 \pm 04$ & 0.13 & -0.06 & -0.10 & 0.01 & 0.00 & & & 0.59 & 0.16 \\
\hline & & & & $16: 16$ & $2105 \pm 04$ & 0.33 & 0.07 & -0.03 & 0.02 & 0.05 & & & & \\
\hline & & & & $16: 33$ & $1461 \pm 07$ & 0.46 & 0.01 & 0.01 & 0.05 & 0.06 & & & & \\
\hline & & & & $16: 48$ & $790 \pm 05$ & 1.05 & -0.01 & -0.01 & 0.08 & 0.16 & 2.11 & 0.13 & & \\
\hline & & & & $17: 03$ & $321 \pm 03$ & 1.85 & 0.19 & 0.07 & 0.11 & 0.16 & 2.36 & 0.13 & & \\
\hline & & & & $17: 15$ & $64 \pm 12$ & 2.43 & 0.02 & 0.01 & 0.16 & 0.25 & 2.54 & 0.16 & & \\
\hline
\end{tabular}




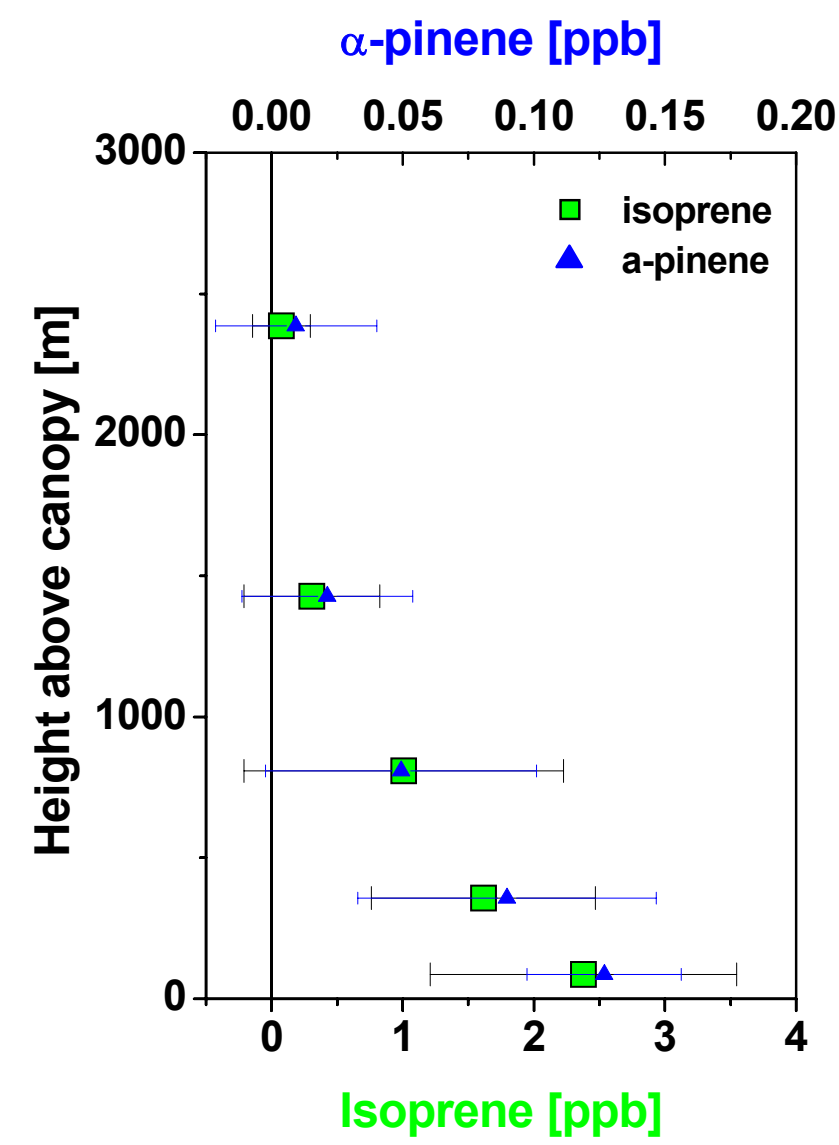

Fig. 8. Mean vertical profiles of observed mixing ratios of isoprene (lower x-axis) and $\alpha$-pinene (upper x-axis), averaged over all airborne measurements analyzed by GC-FID (arithmetic mean \pm standard deviation).

to differences in the general trend of vertical profiles. The strongest concentration gradients were observed close to the surface source (forest canopy), and at the top of the CBL, where free tropospheric air is entrained into the CBL. The small amounts of isoprene and monoterpenes observed in the free troposphere above the CBL are likely attributable to compounds that remained in the residual layer from the previous day, or to deep convection penetrating the CBL. The quasi-exponential attenuation during their upward transport within the CBL is controlled by the relative rates of chemical destruction and turbulent mixing. The similar patterns of isoprene and monoterpenes, both in diel variation (Fig. 4) and in the shape of vertical profiles (Fig. 8), demonstrate the similarities of (i) the environmental functions that are driving the emissions and (ii) the atmospheric lifetimes under the prevailing oxidation regime.

Figure 9 shows the individual VOC profiles for all flights within the CBL, with sampling heights normalized to the individual CBL heights, and the respective functions underlying the MLG flux approach. In general the gradients during
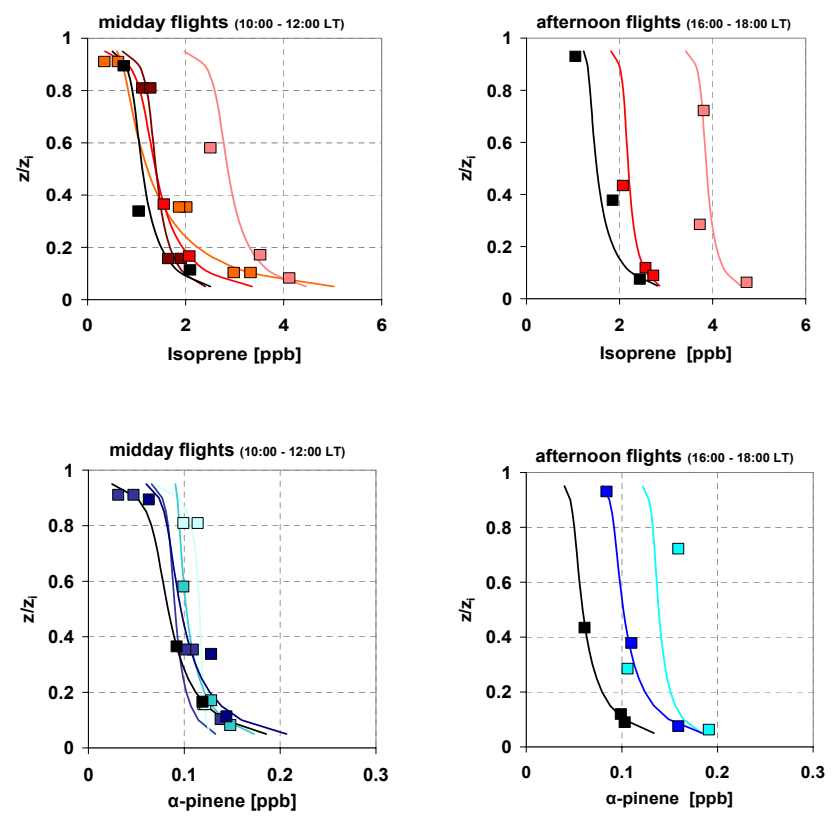

Fig. 9. Observed CBL vertical profiles of isoprene (upper panels) and $\alpha$-pinene (lower panels) at midday (left panels) and afternoon (right panels). Sample heights $(\mathrm{z})$ were normalized by the respective CBL heights $\left(z_{i}\right)$. The lines represent best fits based on the respective MLG functions used to calculate VOC fluxes.

the afternoon flights were somewhat less pronounced compared to the midday flights. Meteorological conditions affect both CBL dynamics, and emission rates. Smaller vertical gradients in the late afternoon may be explained by a reduction of VOC emission due to low radiation intensities close to sunset (compare to REA and SLG results), rather than by enhanced convective mixing.

\subsubsection{Fluxes derived by MLG using observed VOC mixing ratios}

The mixed layer gradient (MLG) approach was applied to each of the flight profiles shown in Fig. 9, to infer individual surface flux estimates. As illustrated in Fig. 10, the MLG fluxes of isoprene and $\alpha$-pinene inferred from the mixing ratios observed across the $\mathrm{CBL}\left(\mathrm{MLG}_{\mathrm{obs}}\right)$ were on average higher by a factor of about two than the fluxes derived from the tower-based measurements (REA and SLG). Applying the recently suggested modification of the MLG equations, to account for plant canopy effects on vertical mixing (Patton et al., 2003), resulted in even higher fluxes, on average $35 \%$. Here only the results obtained with the traditional MLG equations are presented.

The MLG concept assumes that the investigated compounds are conserved scalars, i.e., that they do not decay on timescales equivalent of their vertical mixing within the CBL. For biogenic VOCs that undergo rapid chemical reactions, however, this assumption may not be valid. The 


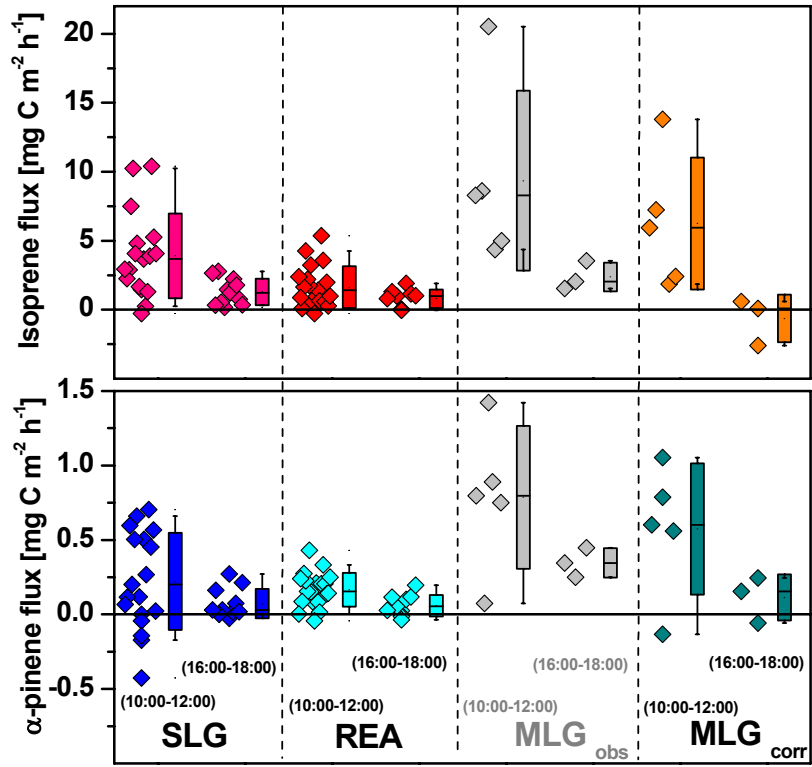

Fig. 10. Comparison of VOC fluxes derived from three different micrometeorological methods, surface layer gradient (SLG, towerbased), relaxed eddy accumulation (REA, tower-based), and mixed layer gradient (MLG, airborne). For tower-based fluxes only data measured within the time frames of the flight measurements are shown, i.e., for midday (10:00-12:00 LT) and afternoon (16:0018:00 LT). The results for the MLG approach shown are inferred from the observed mixing ratio $\left(\mathrm{MLG}_{\mathrm{obs}}\right)$, and by taking into account the chemical degradation of VOC during transport within the $\mathrm{CBL}$ ( $\left.\mathrm{MLG}_{\mathrm{corr}}\right)$. The boxes represent mean values \pm standard deviation, with whiskers at the 1st and 99th percentiles; horizontal solid lines within the boxes are median values.

attenuation (depletion) experienced by biogenic VOCs during their upward transport through the CBL depends mainly on (i) surface exchange, (ii) turbulent mixing, and (iii) chemical destruction. Chemical decay can substantially enhance the vertical scalar gradients and lead to an overestimation of the flux.

The smallest chemical modification to the profiles occurs near the canopy top where the scalar source and scalar gradients are highest, which is why we did not take into account a chemical correction for the tower-based SLG approach. As outlined in detail by Doskey and Gao (1999), measurements of the isoprene flux by gradient and other micrometeorological methods directly above the forest canopy are not significantly influenced by chemical reactions, because vertical gradients of emitted species are mainly controlled by the source strength and turbulent mixing.

Across the CBL, however, strong vertical gradients of isoprene resulting from rapid oxidation have already been predicted by Trainer et al. (1987). In contrast to earlier studies (Davis et al., 1994; Helmig et al., 1998; Spirig et al., 2004), we suggest that in tropical areas the chemical lifetime of isoprene and $\alpha$-pinene may be of similar magnitude
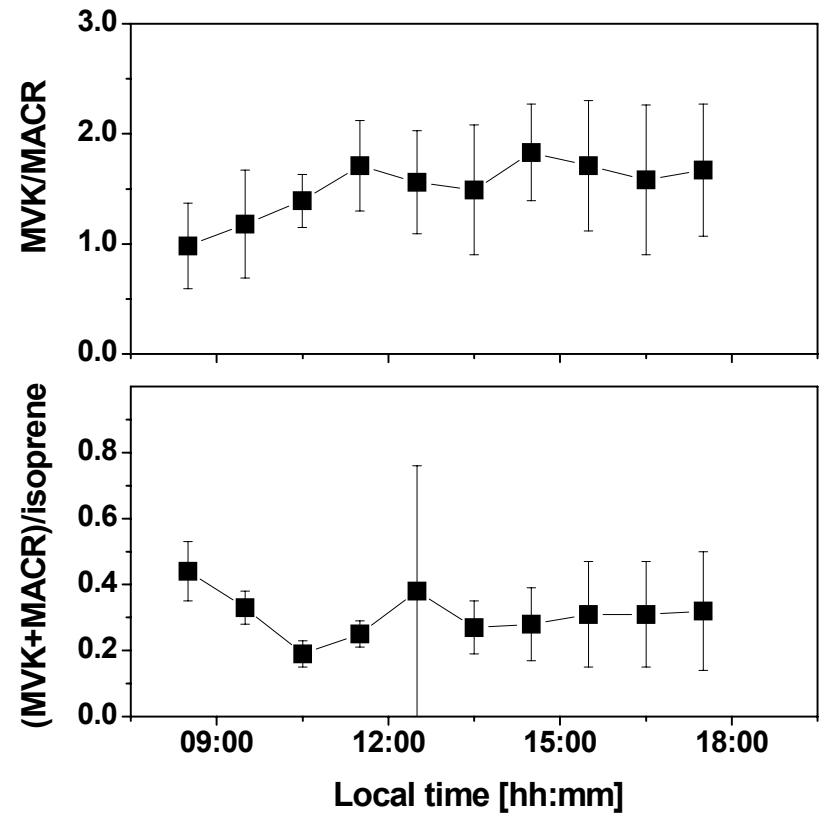

Fig. 11. Observed ratios of MVK/MACR and $(\mathrm{MVK}+\mathrm{MACR}) /$ isoprene (hourly mean values \pm standard deviation) derived by tower-based measurements at $21 \mathrm{~m}$ above canopy. The relatively high error bar of (MVK+MACR)/isoprene at 13:00 LT is due to one outlier.

as the turnover time within the CBL, and that chemistry has to be taken into account when applying the MLG approach. The chemical lifetimes of biogenic VOCs in the CBL are estimated to be on the order of minutes to hours, depending primarily on the concentrations of $\mathrm{OH}$ radicals and ozone, as will be detailed below.

\subsubsection{MVK/MACR ratios and implications for isoprene ox- idation}

The atmospheric degradation of isoprene during daytime is primarily initiated by reaction with $\mathrm{OH}$ or $\mathrm{O}_{3}$, and it can involve several thousand subsequent reactions and hundreds of intermediate species (Pöschl et al., 2000; Saunders et al., 2003). The relative importance of these reaction pathways can be inferred from the ratio of the primary oxidation products methacrolein $\left(\mathrm{CH}_{2} \mathrm{CCH}_{3} \mathrm{CHO}, \mathrm{MACR}\right)$ and methyl vinyl ketone $\left(\mathrm{CH}_{2} \mathrm{CHCOCH}_{3}, \mathrm{MVK}\right)$.

Oxidation of isoprene by $\mathrm{OH}$ in the presence of $\mathrm{NO}_{\mathrm{x}}$ produces MVK and MACR with yields of $32 \%$ and 23\%, respectively (Tuazon and Atkinson, 1990). Thus the ratio MVK/MACR would be $\sim 1.4$, if MVK and MACR would not undergo further reaction. Oxidation by $\mathrm{OH}$, however, removes MACR more quickly than MVK and further increases the MVK/MACR ratio. In contrast, oxidation of isoprene by $\mathrm{O}_{3}$ yields more MACR than MVK, and MVK reacts more quickly with $\mathrm{O}_{3}$ than MACR. Thus ozone-dominated 

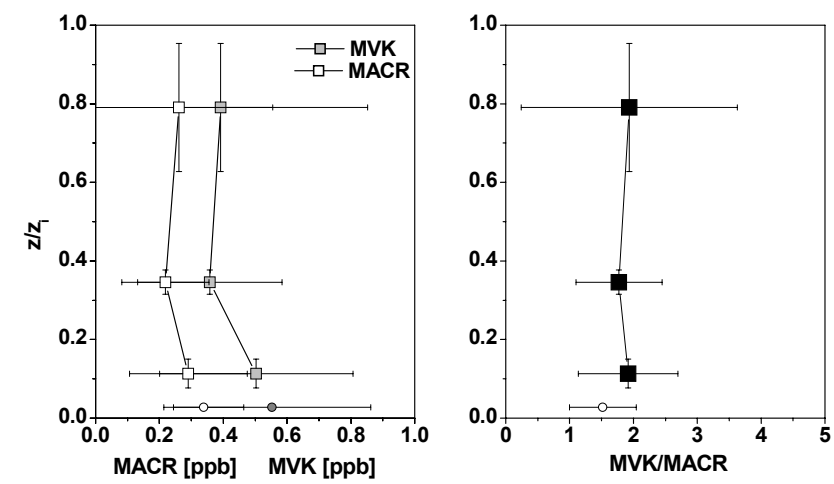

Fig. 12. Mean mixing ratios of MVK and MACR and the ratio of MVK/MACR of all airborne vertical profile measurements analyzed by GC-FID. Sample heights $(z)$ were normalized by the respective CBL heights $\left(z_{i}\right)$.

isoprene oxidation would result in MVK/MACR ratios lower than 0.4 (Carter and Atkinson, 1996).

The tower-based measurements at $21 \mathrm{~m}$ above canopy top, averaged over the whole period $(n=51)$, revealed mean daytime mixing ratios of $3.4 \pm 1.8,0.55 \pm 0.31$ and $0.34 \pm 0.13 \mathrm{ppb}$, (median 3.2, 0.49 and $0.34 \mathrm{ppb}$ ) for isoprene, MVK and MACR. As shown in Fig. 11, the diel course of the MVK/MACR ratio showed a regular diel pattern, with mean daytime values above 1.4 , indicative of $\mathrm{OH}$-dominated isoprene degradation. Close to the canopy top the production of MVK and MACR is supposed to be largest (due to high isoprene mixing ratios) and the influence of further oxidation is small. Also the mean velocity shear is largest in this surface layer, with the largest turbulence kinetic energy; hence here the smallest chemical modification occurs. This is different for the airborne data within the CBL, where the chemical production of MVK and MACR is smaller (due to lower isoprene mixing ratios) and the compounds are subject to chemical degradation for longer time periods.

Figure 12 shows the mean vertical profiles of MVK and MACR and the respective ratios during the airborne measurements within the CBL (GC-FID data). The observed MVK/MACR ratio is consistently close to $\sim 2$ throughout the CBL, which is in accordance with tethered balloon measurements in other tropical areas (Greenberg et al., 1999), and gives evidence for an $\mathrm{OH}$-dominated oxidation regime in the lower tropical troposphere, confirming that ozonolysis did not play an important role in isoprene degradation.

\subsection{4 (MVK+MACR)/ISO ratios and implications for} chemistry and transport

Further information about atmospheric chemistry and transport can be derived from the ratio of the sum of MVK and MACR over isoprene, (MVK+MACR)/ISO. During the day, (MVK+MACR)/ISO is mainly driven by the OH chemistry, which destroys isoprene while producing (and concurrently

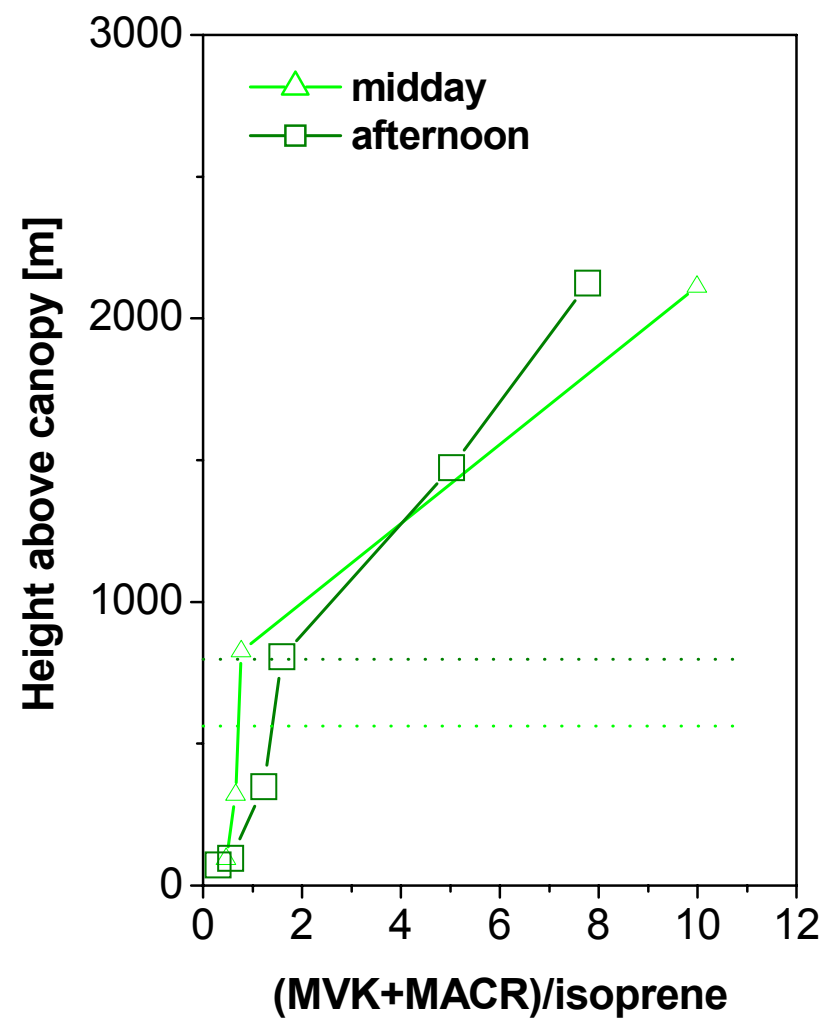

Fig. 13. Observed vertical profiles of (MVK+MACR)/isoprene derived by GC-MS analysis during the midday (10:00-12:00 LT; CBL top $550 \mathrm{~m}$ ) and the afternoon (16:00-18:00 LT; CBL top $800 \mathrm{~m}$ ) flights on 11 July 2001. Dotted lines indicate the respective CBL tops.

destroying) MVK and MACR. As for every reactive scalar, the vertical profile of (MVK+MACR)/ISO is a function of turbulent mixing, surface deposition, distance from the emission source (transport time), and photochemical degradation (Montzka et al., 1995; Biesenthal et al., 1998; Barket et al., 2004).

With regard to nitrogen oxides, Biesenthal et al. (1998) have described a logarithmic dependence of $(\mathrm{MVK}+\mathrm{MACR}) / \mathrm{ISO}$ on the average mixing ratio of $\mathrm{NO}_{\mathrm{x}}$ $\left(=\mathrm{NO}+\mathrm{NO}_{2}\right)$ from several campaigns and spanning a wide range of $\mathrm{NO}_{\mathrm{x}}$ regimes. The average $(\mathrm{MVK}+\mathrm{MACR}) / \mathrm{ISO}$ for the CLAIRE tower-based measurement period was $0.31 \pm 0.07(n=51)$ at $21 \mathrm{~m}$ above the canopy, and did not show strong variations during daytime (Fig. 11), which is in good agreement with earlier observations at a similar Amazon tropical forest tower site (Kesselmeier et al., 2002). These values are consistent with the relationship of Biesenthal et al. (1998) and with low daytime $\mathrm{NO}_{\mathrm{x}}$ levels $(<500 \mathrm{ppt})$ reported for comparable Amazon rainforest sites (Andreae et al., 2002).

Figure 13 shows the observed vertical profiles of (MVK+MACR)/ISO for the two flights that were measured 


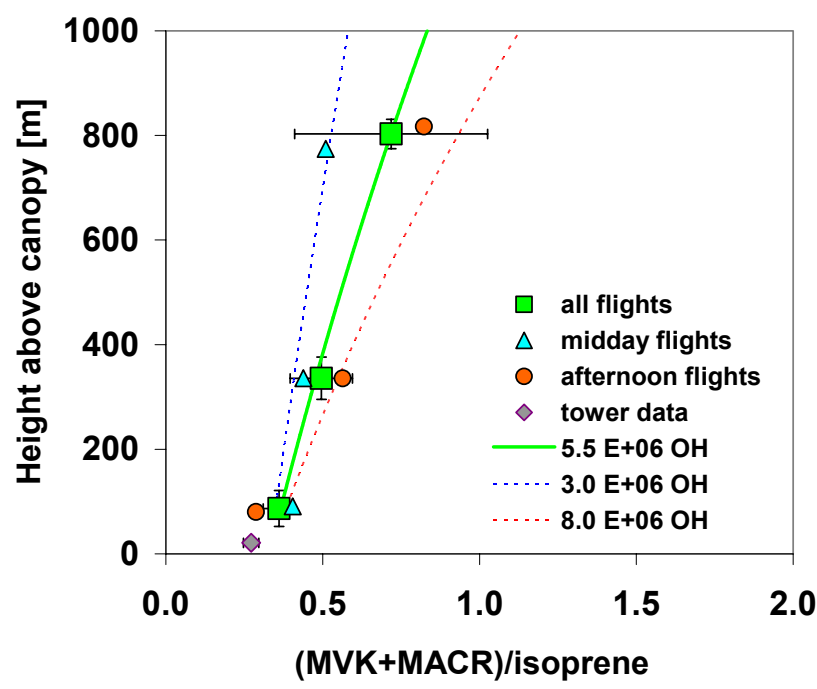

Fig. 14. Observed vertical profiles of (MVK+MACR)/ISO within the CBL derived by GC-FID analysis: midday (cyan triangles) and afternoon flights (red circles) flights, and mean values of all flights (green squares, \pm 1 standard error). The mean value of the towerbased measurements in the respective time frames, at $21 \mathrm{~m}$ above the canopy, is also shown (grey diamond, \pm 1 standard error). The lines represent prognostic vertical profiles of (MVK+MACR)/ISO derived from Eqs. (7), (8), and (9), using the mean ratios and different $\mathrm{OH}$ radical concentrations, of 3 and $8 \times 10^{6}$ molecules $\mathrm{cm}^{-3}$ (dotted lines), and the best estimate of $5.5 \times 10^{6}$ molecules $\mathrm{cm}^{-3}$ (solid line).

with GC-MS (midday and afternoon on 11 July 2001). The ratio increased several-fold within the CBL, in close agreement with Helmig et al. (1998) who reported an increase of the ratios $\mathrm{MVK} /$ isoprene and MACR/isoprene with height within the CBL using tethered balloon soundings at a remote Peruvian Amazon rainforest site. As shown in Fig. 13, a stronger gradient for (MVK+MACR)/ISO was observed in the afternoon compared to midday. This difference is in line with the convective velocity scales calculated for the afternoon and midday flight (of $1 \mathrm{~m} \mathrm{~s}^{-1}$ and $1.3 \mathrm{~m} \mathrm{~s}^{-1}$ ), as a slower convective velocity scale leads to longer mixing time scales and chemical processing times, respectively.

Accordingly, the even higher (MVK+MACR)/ISO ratios above the CBL can be understood due to the preferential removal of isoprene over its longer-lived oxidation products, by reactions with $\mathrm{OH}$ and ozone during long-term transport in the lower free troposphere, subsequent to convective mixing by low level cumulus clouds. The trend shown in the two individual GC-MS data sets was also confirmed by the majority of GC-FID data (8 flights), as shown for the mean values within the CBL in Fig. 14. The GC-MS data systematically indicated lower mixing ratios for both isoprene and its primary degradation products, and therefore a similar trend of (MVK+MACR)/ISO was derived by both analytical systems. As for the GC-MS data, stronger gradients of
(MVK+MACR)/ISO were found in the afternoon compared to the midday flights by GC-FID analysis (Fig. 14). Above the CBL the GC-FID data showed a very high scatter (data not shown), which may be explained by the fact that values of the ratio's denominator close to zero easily lead to spurious values.

\subsection{5 $\mathrm{OH}$ concentrations inferred from (MVK+MACR)/ISO profiles}

As there are no direct measurements of $\mathrm{OH}$ radical concentrations published for the tropical CBL yet, we have made an attempt to infer $\mathrm{OH}$ concentrations by fitting a simple chemical kinetics model to the observed profiles of the $(\mathrm{MVK}+\mathrm{MACR}) / \mathrm{ISO}$ ratio. In this "back-of-the-envelope" approach, we assume that the rates of turbulent mixing and surface deposition velocities are similar for all three compounds, i.e., that differences do not play a significant role during the time of transport from the canopy to the altitude of observation. Under these conditions the change of (MVK+MACR)/ISO with altitude can be calculated as a function of transport time and reactant concentrations.

The chemical loss of isoprene by reaction with $\mathrm{OH}$ and $\mathrm{O}_{3}$ can be described by

$\frac{\partial[\mathrm{ISO}]}{\partial t}=-\left(k_{\mathrm{ISO}, \mathrm{OH}} \times[\mathrm{OH}]+k_{\mathrm{ISO}, \mathrm{O}_{3}} \times\left[\mathrm{O}_{3}\right]\right) \times[\mathrm{ISO}]$

where [ISO], $[\mathrm{OH}]$, and $\left[\mathrm{O}_{3}\right]$ are the reactant concentrations (number densities), and $k_{\mathrm{ISO}, \mathrm{OH}}$ and $k_{\mathrm{ISO}, \mathrm{O}_{3}}$ are the reaction rate coefficients of the reactions of isoprene with $\mathrm{OH}$ and $\mathrm{O}_{3}$ (Table 4). The net chemical production of MVK and MACR can be described by

$$
\begin{aligned}
& \frac{\partial[\mathrm{MVK}]}{\partial t}=y_{\mathrm{MVK}, \mathrm{OH}} \times\left(\frac{\partial[\mathrm{ISO}]}{\partial t}\right)_{\mathrm{OH}} \\
& +y_{\mathrm{MVK}, \mathrm{O}_{3}} \times\left(\frac{\partial[\mathrm{ISO}]}{\partial t}\right)_{\mathrm{O}_{3}} \\
& -\left(k_{\mathrm{MVK}, \mathrm{OH}} \times[\mathrm{OH}]+k_{\mathrm{MVK}, \mathrm{O}_{3}} \times\left[\mathrm{O}_{3}\right]\right) \times[\mathrm{MVK}] \\
& \frac{\partial[\mathrm{MACR}]}{\partial t}=y_{\mathrm{MACR}, \mathrm{OH}} \times\left(\frac{\partial[\mathrm{ISO}]}{\partial t}\right)_{\mathrm{OH}} \\
& +y_{\mathrm{MACR}, \mathrm{O}_{3}} \times\left(\frac{\partial[\mathrm{ISO}]}{\partial t}\right)_{\mathrm{O}_{3}} \\
& -\left(k_{\mathrm{MACR}, \mathrm{OH}} \times[\mathrm{OH}]+k_{\mathrm{MACR}, \mathrm{O}_{3}} \times\left[\mathrm{O}_{3}\right]\right) \times[\mathrm{MACR}]
\end{aligned}
$$

where $y_{\mathrm{MVK}, \mathrm{OH}}=0.31$ and $y_{\mathrm{MACR}, \mathrm{OH}}=0.20$ are the yields of MVK and MACR from isoprene reaction with $\mathrm{OH}$ in the presence of $\mathrm{NO}_{\mathrm{x}}$ (Ruppert and Becker, 2000); $y_{\mathrm{MVK}, \mathrm{O}_{3}}=0.17$ and $y_{\mathrm{MACR}, \mathrm{O}_{3}}=0.41$ are the estimated yields of MVK and MACR from isoprene reaction with $\mathrm{O}_{3}$ (IUPAC); $k_{\mathrm{MVK}, \mathrm{OH}}, k_{\mathrm{MVK}, \mathrm{O}_{3}}, k_{\mathrm{MACR}, \mathrm{OH}}$ and 
Table 4. Rate coefficients, photodissociation rates, and respective atmospheric lifetimes of selected VOC at $298^{\circ} \mathrm{K}$. Atmospheric lifetimes assume an $\mathrm{OH}$ radical concentration of $2.0 \times 10^{6}$ molecules $\mathrm{cm}^{3}$ on 12 -h average and $\mathrm{O}_{3}$ concentration of $7 \times 10^{11}$ molecules $\mathrm{cm}^{3}(\sim 29 \mathrm{ppb})$ on a 24-h average. ${ }^{\mathrm{a}}$ Atkinson (2005); ${ }^{\mathrm{b}}$ Atkinson (2003); ${ }^{\mathrm{c}}$ Plagens (2001); ${ }^{\mathrm{d}}$ Kwok and Atkinson (1995); ${ }^{\mathrm{e}}$ Bowman et al. (2003); ${ }^{\mathrm{f}}$ Moortgat (2001); ${ }^{\mathrm{g}}$ Hellen (2004).

\begin{tabular}{lllllll}
\hline compound & $k_{\mathrm{OH}}\left[\mathrm{cm} \mathrm{molecule} \mathrm{e}^{-1} \mathrm{~s}^{-1}\right]$ & $\tau_{\mathrm{OH}}$ & $k_{\mathrm{O}_{3}}\left[\mathrm{~cm}^{3}\right.$ molecule $\left.{ }^{-1} \mathrm{~s}^{-1}\right]$ & $\tau_{\mathrm{O}_{3}}$ & photolytic rate & $\tau_{\text {phot }}$ \\
\hline isoprene & $1.0 \mathrm{E}-10^{\mathrm{a}}$ & $1.4 \mathrm{~h}^{\mathrm{b}}$ & $1.27 \mathrm{E}-17^{\mathrm{a}}$ & $1.3 \mathrm{~d}^{\mathrm{b}}-$ & - \\
$\alpha$-pinene & $5.3 \mathrm{E}-11^{\mathrm{a}}$ & $2.6 \mathrm{~h}^{\mathrm{b}}$ & $9.00 \mathrm{E}-17^{\mathrm{a}}$ & $4.6 \mathrm{~h}^{\mathrm{b}}-$ & - \\
MVK & $2.0 \mathrm{E}-11^{\mathrm{a}}$ & $6.9 \mathrm{~h}^{\mathrm{b}}$ & $5.20 \mathrm{E}-18^{\mathrm{a}}$ & $3.4 \mathrm{~d}^{\mathrm{b}}$ & $<1 \mathrm{E}-6^{\mathrm{f}}$ & $>6 \mathrm{~d}^{\mathrm{f}}$ \\
MACR & $2.9 \mathrm{E}-11^{\mathrm{a}}$ & $4.8 \mathrm{~h}^{\mathrm{b}}$ & $1.20 \mathrm{E}-18^{\mathrm{a}}$ & $15 \mathrm{~d}^{\mathrm{b}}$ & $<1 \mathrm{E}-6^{\mathrm{f}}$ & $>6 \mathrm{~d}^{\mathrm{f}}$ \\
nonanal & $2.9 \mathrm{E}-11^{\mathrm{c}}, 3.3 \mathrm{E}-11^{\mathrm{d}}, 3.6 \mathrm{E}-11^{\mathrm{e}}$ & $5.0 \mathrm{~h}^{\mathrm{f}}$ & - & - & $1.15 \mathrm{E}-5^{\mathrm{f}}$ & $1 \mathrm{~d}^{\mathrm{f}}, 1.6 \mathrm{~d}^{\mathrm{g}}$ \\
\hline
\end{tabular}

$k_{\mathrm{MACR}, \mathrm{O}_{3}}$ are the rate coefficients of the reactions of MVK and MACR with $\mathrm{OH}$ and $\mathrm{O}_{3}$, respectively (Table 4$)$; and $(d[\mathrm{ISO}] / d t)_{\mathrm{OH}}=k_{\mathrm{ISO}, \mathrm{OH}} \times[\mathrm{ISO}] \times[\mathrm{OH}]$ and $(d[\mathrm{ISO}] / d t)_{\mathrm{O}_{3}}=k_{\mathrm{ISO}, \mathrm{O}_{3}} \times[\mathrm{ISO}] \times\left[\mathrm{O}_{3}\right]$ derived from Eq. (7).

The transport and reaction time $t$, after which a certain profile height $z$ is reached by trace constituents ascending from the canopy, was approximated by a generalized form of Eq. (6), as

$t=\frac{z}{w^{*}}$

The temporal evolution of (MVK+MACR)/ISO was simulated by iterative integration of the above equations with a standard spreadsheet program (Microsoft Excel 2003; $1 \mathrm{~s}$ time steps) assuming constant temperature and pressure $\left(298^{\circ} \mathrm{K}, 1 \mathrm{~atm}\right)$. As concurrent surface measurements were not available during the flights, the mean ISO, MACR, and MVK mixing ratios measured at the lowermost flight altitudes $(87 \pm 34 \mathrm{~m}$ above canopy, see Table 3$)$ were used as starting conditions for the numerical integration $\left(z_{0}=\right.$ canopy top). The $\mathrm{O}_{3}$ mixing ratios in the $\mathrm{CBL}$ ranged between $10-20 \mathrm{ppb}$ during all flights, and were set to $15 \mathrm{ppb}$ in all model calculations. The $\mathrm{OH}$ concentration was adjusted to fit the calculated prognostic vertical profiles to the observed profiles of (MVK+MACR)/ISO. As shown in Fig. 14, best fits of the chemical kinetics model to observations were obtained with $\mathrm{OH}$ concentrations in the range of 3$8 \times 10^{6}$ molecules $\mathrm{cm}^{-3}$ (dotted lines in Fig. 14), with a best estimate for all flights of $5.5 \times 10^{6}$ molecules $\mathrm{cm}^{-3}$ (solid line in Fig. 14). Assuming $\mathrm{NO}_{\mathrm{x}}$ free conditions, generating altered yields of MVK and MACR from isoprene reaction with $\mathrm{OH}\left(y_{\mathrm{MVK}, \mathrm{OH}}=0.15\right.$ and $y_{\mathrm{MACR}, \mathrm{OH}}=0.18$; Ruppert and Becker, 2000), an even higher best guess OH concentration of about $7.5 \times 10^{6}$ molecules $\mathrm{cm}^{-3}$ is calculated. Likewise, a best estimate $\mathrm{OH}$ radical concentration of about $9.8 \times 10^{6}$ molecules $\mathrm{cm}^{-3}$ is achieved by using the numbers for isoprene, MVK and MACR measured by the GC-MS system (two flights).

A similar kind of estimation was used by Helmig et al. (1998) to infer convective turnover time scales within the
CBL over the Amazon rain forest of Peru from measured $\mathrm{MVK} /$ isoprene and MACR/isoprene ratios, assuming predefined $\mathrm{OH}$ concentrations of $4.5 \times 10^{6}$ molecules $\mathrm{cm}^{-3}$. The (MVK+MACR)/ISO was also applied by Stoud et al. (2001) to infer the photochemical age of air masses.

An alternative approach to derive mean $\mathrm{OH}$ concentrations is to apply a simple budget analysis on mean CBL mixing ratios and respective fluxes to infer $\mathrm{OH}$ radical concentrations (e.g., T. Karl et al., 2007). Assuming that the isoprene mixing ratio is in steady state within the CBL, the amount of isoprene emitted $\left(F_{\mathrm{ISO}}\right)$ is counter-balanced by the amount that is chemically degraded at the same time. According to Eq. (7), the respective flux-to-lifetime relationship can then be described as

$$
F_{\mathrm{ISO}}=\left(k_{\mathrm{OH}(\mathrm{ISO})} \times[\mathrm{OH}]+k_{\mathrm{O}_{3}(\mathrm{ISO})} \times\left[\mathrm{O}_{3}\right]\right) \times[\mathrm{ISO}] \times z_{i}
$$

Solving Eq. (11) for $\mathrm{OH}$, using the observed CBL mean isoprene mixing ratio of $1.5 \mathrm{ppb}$ (Fig. 8) and MLG mean midday isoprene fluxes of $6.2 \mathrm{mg} \mathrm{C} \mathrm{m}^{-2} \mathrm{~h}^{-1}$ that were calculated from the respective vertical CBL profiles (Fig. 10), results in $\mathrm{OH}$ radical concentrations of $4.5 \times 10^{6}$ molecules $\mathrm{cm}^{-3}$. The uncertainty on the impact of entrainment fluxes of the MLG approach transfers approximately linearly to the uncertainty in estimating $\mathrm{OH}$. Based on flux rates obtained by towerbased REA measurements (1.5-5.5 $\mathrm{mg} \mathrm{C} \mathrm{m}^{-2} \mathrm{~h}^{-1}$, Fig. 6), the range of estimated $\mathrm{OH}$ radical concentrations would be $1.0-4.0 \times 10^{6}$ molecules $\mathrm{cm}^{-3}$.

The $\mathrm{OH}$ radical concentrations derived from both, the back-of-the-envelope calculation on observed (MVK+MACR)/ISO ratios (Eq. 7-10), and from the simple budget analysis (Eq. 11) are about an order of magnitude higher than estimated earlier. For the CBL above the tropical forest of Suriname, Warneke et al. (2001) predicted OH concentrations as low as $1-3 \times 10^{5}$ molecules $\mathrm{cm}^{-3}(24 \mathrm{~h}$ average), and Williams et al. (2001) suggested a range of $0.6-1.1 \times 10^{6}$ molecules $\mathrm{cm}^{-3}$ as maximal daytime values. Likewise, $\mathrm{OH}$ concentrations of $2 \times 10^{5}$ molecules $\mathrm{cm}^{-3}$ were derived from variability-lifetime analysis of VOCs along back trajectories (Williams et al., 2000) and from 
simulations with the chemistry and tracer transport model TM3 (Lelieveld et al., 2002, 2004). Most recent calculations by Karl et al. (2007) revealed $\mathrm{OH}$ radical concentrations of $1-5 \times 10^{5}$ molecules $\mathrm{cm}^{-3}$ for the planetary boundary layer over the Amazonian rainforest, using a 0-dimensional photochemical box model including the NCAR Master Mechanism, and $1.3 \pm 0.5 \times 10^{6}$ molecules $\mathrm{cm}^{-3}$ using a simple box technique. Their best estimate average $\mathrm{OH}$ of the lower atmosphere (including the cloud layer) was $0.7-$ $1.5 \times 10^{6}$ molecules $\mathrm{cm}^{-3}$, due to the influence of increased $\mathrm{OH}$ production within the cloud layer.

In current chemistry and transport models, isoprene oxidation is assumed to account for a massive reduction of OH concentrations (Grosjean, 1995; Poisson et al., 2000; Roelofs and Lelieveld, 2000). In contrast, our empirical estimate compares to typical concentrations of $\mathrm{OH}$ in a moderately polluted atmosphere. Similarly, Tan et al. (2001) also observed $\mathrm{OH}$ concentrations $\left(\sim 4 \times 10^{6}\right.$ molecules $\left.\mathrm{cm}^{-3}\right)$ much higher than model-predicted, in a high isoprene and low $\mathrm{NO}_{\mathrm{x}}$ environment $10 \mathrm{~m}$ above a northern Michigan forest canopy. They concluded that even a postulated additional $\mathrm{OH}$ source from the ozonolysis of undetected VOCs was insufficient to account for the observed high " $\mathrm{OH}$ reactivity" (see also Di Carlo et al., 2004). Accordingly, Dreyfus et al. (2002) reported a mean $\mathrm{OH}$ concentration of 9 $( \pm 4) \times 10^{6}$ molecules $\mathrm{m}^{-3}$, deduced from MVK/MACR ratios observed at a rural Sierra Nevada Mountain site, which was influenced by an adjacent high isoprene emitting oak forest. Most recently, Kleffmann et al. (2005) measured the diurnal variation and, for the first time, determined the vertical distribution of $\mathrm{OH}$ in and above a mixed deciduous temperate forest site in a rural area of Germany. They also reported remarkably high midday concentrations of 4$9 \times 10^{6}$ molecules $\mathrm{cm}^{3}$ above the canopy, dependent on the variation of solar ultraviolet radiation. Unfortunately, direct measurements of $\mathrm{OH}$ are not yet available within the CBL of a tropical forest, but the aforementioned references seem to support the results of our back-of-the-envelope calculation.

The predominance of isoprene, combined with its high reactivity, is likely the key factor in $\mathrm{OH}$ reactivity (Di Carlo et al., 2004). The production of $\mathrm{OH}$ radicals in general is expected to be at maximum in the tropics, where the solar zenith angle is smallest, the stratospheric ozone layer is thinnest, and the air humidity is highest (Lelieveld et al., 2004). Oxidation of biogenic VOCs by $\mathrm{OH}$ in the presence of $\mathrm{NO}_{\mathrm{x}}$ is the principal source of tropospheric $\mathrm{O}_{3}$ (Kleinman et al., 2002; Ryerson et al., 2001). However, ozone produced near the surface in the central tropics is expected to be rapidly destroyed via photolysis forming $\mathrm{OH}$, due to a combination of low stratospheric column density, high relative humidity, and temperature. Likewise, significant $\mathrm{OH}$ radical formation by the reactions of ozone with isoprene and monoterpenes and their degradation products has been suggested during both daytime and nighttime (Paulson and Orlando, 1996; Paulson et al., 1997; Donahue et al., 1998;
Pfeiffer et al., 1998; Kroll et al., 2002). Moreover, Goldstein et al. (2004) inferred that a significant part of the total ozone flux into a California pine forest ecosystem was due to chemical loss by reaction with VOC within the forest canopy; and large quantities of previously unquantified oxidation products of precursor VOC have been reported by Holzinger et al. (2005). The authors state that these shortlived biogenic VOC (likely terpenoid compounds) might impact tropospheric composition, as they could efficiently produce hydroxyl radicals when oxidized by ozone.

\subsubsection{MLG fluxes using chemically corrected VOC mixing ratios}

The best-estimate mean $\mathrm{OH}$ concentration of $5.5 \times 10^{6}$ molecules $\mathrm{cm}^{3}$ and observed mean $\mathrm{O}_{3}$ mixing ratios of $15 \mathrm{ppb}$ were used to correct all isoprene and $\alpha$-pinene vertical profile data within the CBL according to Eqs. (7) and (10). Under these conditions, the isoprene chemical degradation was by far dominated by the reaction with $\mathrm{OH}$, and the contribution of ozonolysis was calculated to be only about $1 \%$. On the other hand, $\alpha$-pinene reacts more slowly with $\mathrm{OH}$, whereas the reaction of ozone with $\alpha$-pinene is approximately ten times faster than with isoprene (Table 4), which partly compensates for the slower $\mathrm{OH}$-dependent degradation, revealing a mean contribution of ozonolysis on $\alpha$-pinene degradation of about $13 \%$.

The chemical reactions of VOCs during transport within the CBL (canopy to CBL top) led to a reduction of the vertical gradients by, on average, $40 \%$ (30-57\%) for isoprene and $26 \%$ (19-40\%) for $\alpha$-pinene, dependent on the estimated CBL heights and calculated convective velocity scales of the individual flights. The consequential reductions of calculated MLG fluxes were of the same magnitude (on average $54 \%$ for isoprene and $33 \%$ for $\alpha$-pinene), irrespective of whether the traditional (Davis et al., 1994) or modified (Patton et al., 2003) MLG-equations were applied. The derived adjusted MLG fluxes for each CBL profile and supplementary parameters of the airborne measurements used for the MLG flux calculations are listed in Table 3. A compilation of all tower-based flux data together with the fluxes calculated from airborne measurements with/without consideration of a chemical adjustment is shown in Fig. 10. Only by taking into account the substantial chemical degradation of observed VOC mixing ratios a reasonable agreement between MLG fluxes and those derived by tower-based measurements was achieved. It has to be noted that the towerbased measurements were conducted in the week after the airborne measurement campaign, which also might have contributed to the bias of results. However, the weather conditions were similar in both measurement periods, and only the respective daytime hours of the flights (10:00-12:00 and 16:00-18:00 LT) were selected for tower-based VOC fluxes shown in the comparison (Fig. 10). 
An alternative method to test the different impacts of the time scales of turbulent mixing and chemistry is to find a scalar that is emitted from the same source, but does not chemically decay on the time scale of convective turnover. Nonanal is found ubiquitously in forest environments, and biogenic emissions are reported in the literature (Ciccioli et al., 1993; Owen et al., 1997; Kirstine et al., 1998; Wildt et al., 2003; Ieda et al., 2006), hence the source distribution of this compound can be assumed to be similar to isoprene and $\alpha$-pinene. Nonanal has an atmospheric lifetime of several hours (assuming $5 \times 10^{6}$ molecules $\mathrm{cm}^{-3} \mathrm{OH}$; roughly a factor of 3 longer than isoprene; Moortgat, 2001) and is not likely to be produced in the remote atmosphere by chemical reactions (Matsunaga et al., 2003), so that nonanal seems to be a good candidate to infer the role of turbulent mixing within the CBL. Nonanal is produced from the ozonolysis of unsaturated fatty acid lipids, which are components of the plant epicuticular waxes (Fruekilde et al., 1997; Bowman et al., 2003). The downside of using nonanal is that there are potential interactions (production or deposition) with atmospheric particulate matter (Matsunaga et al., 2003; Bowman et al., 2003; Moise and Rudich, 2002) whose impact on vertical profiles of nonanal can not yet be assessed. Also, there might be potential artefacts during the sampling and analytical procedure (Helmig et al., 1996).

The observed absolute mixing ratios of nonanal during the airborne measurements of LBA-CLAIRE 2001 were in the low ppt range (Fig. 15) and the vertical profiles revealed a large scatter. Nevertheless, keeping in mind the uncertainty of this approach, the observed mean values of nonanal showed a vertical profile as expected for a compound emitted by the forest. Presuming that nonanal is biogenic and can be considered as a conserved scalar within the time scales of CBL convective turnover, its depletion with height is largely driven by turbulent mixing. The observed depletion of nonanal between the upper- and lowermost sampling heights within the CBL was on average only $25 \%$, compared to an observed isoprene depletion of 58\% (54\% for $\alpha$-pinene) (Fig. 15). This rough estimate would indicate that the residual impact of chemical destruction in isoprene depletion on average would be about $33 \%$ for isoprene (29\% for $\alpha$-pinene). These values are within a similar range as the respective chemical corrections of $31 \%$ for isoprene (19\% for $\alpha$-pinene), calculated by Eq. (7) using a best-estimate $\mathrm{OH}$ concentration of $5.5 \times 10^{6}$ molecules $\mathrm{cm}^{-3}$ (Fig. 15). If chemical degradation of nonanal within the CBL were considered, an even slightly larger role of chemistry versus transport would be implicit from this approach.

\subsubsection{SCM results on atmospheric chemistry}

We are aware that the estimate of $\mathrm{OH}$ radical concentrations presented above ignores the possible impact of biosphereCBL-free troposphere exchanges, dry deposition removal, and an expected, but yet unknown, vertical gradient of $\mathrm{OH}$

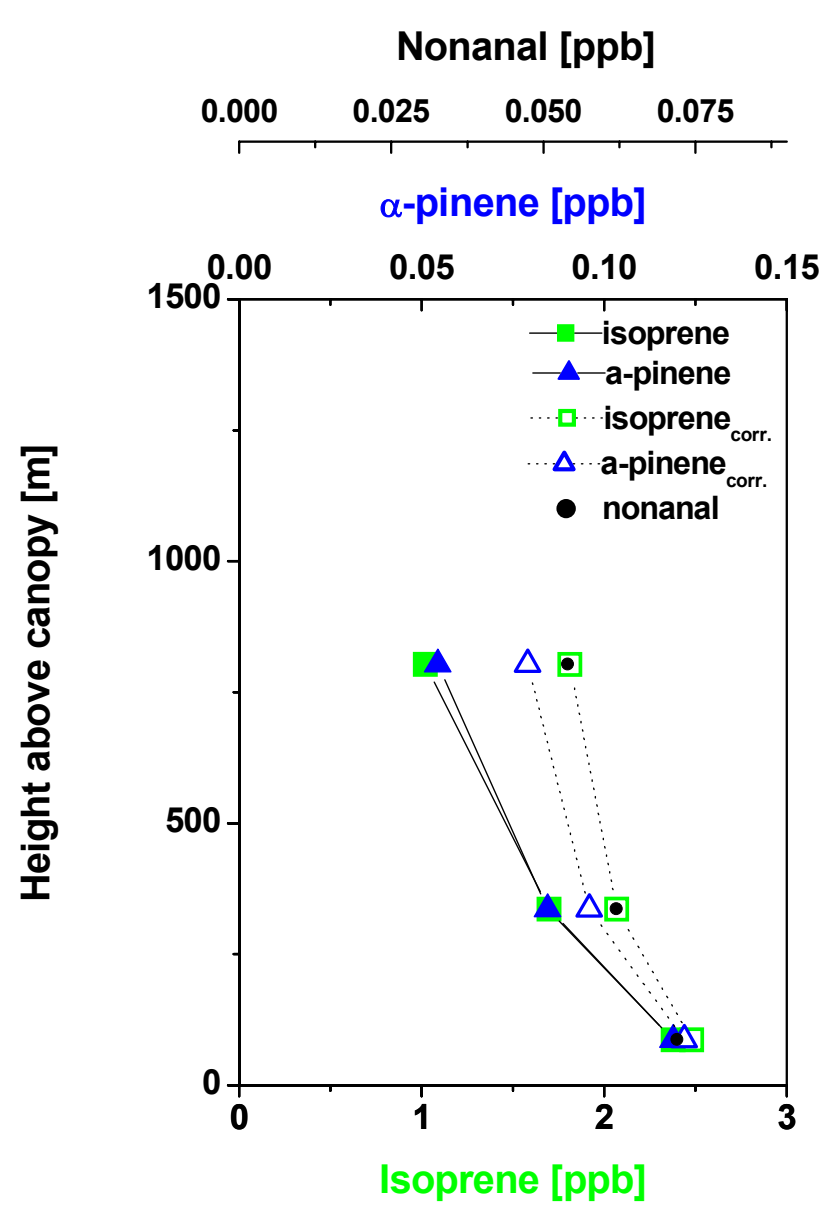

Fig. 15. Observed and chemistry adjusted vertical profiles of isoprene (squares) and $\alpha$-pinene (triangles). For comparison the observed vertical profile of nonanal (circles) is shown, which is assumed to be a scalar emitted from the forest canopy, but conserved within the time scales of convective turnover.

affecting the simulated mixing ratios of isoprene and its oxidation products. To explore these issues, the modification of the vertical isoprene profiles associated with the chemical oxidation involving $\mathrm{O}_{3}, \mathrm{OH}$, and $\mathrm{NO}_{3}$, and the build-up of degradation products has also been simulated with the above mentioned single-column chemistry and climate model.

Figure 16 shows the model-simulated midday and afternoon vertical profiles of (MVK+MACR)/ISO for 20 July 2001, a period when the conditions were approximately representative of the study period. The modelled vertical profiles of this ratio are comparable to the observations, i.e., in good agreement in the middle of the PBL, but with lower values close to the surface, and larger values close to the CBL top. Still, during daytime the absolute mixing ratios of isoprene (and to a lesser extent MVK and MACR) are a factor of 2-3 higher in the model than in the observations, especially close to the surface. In spite of a good representation of the simulated isoprene flux, the SCM model analysis on 


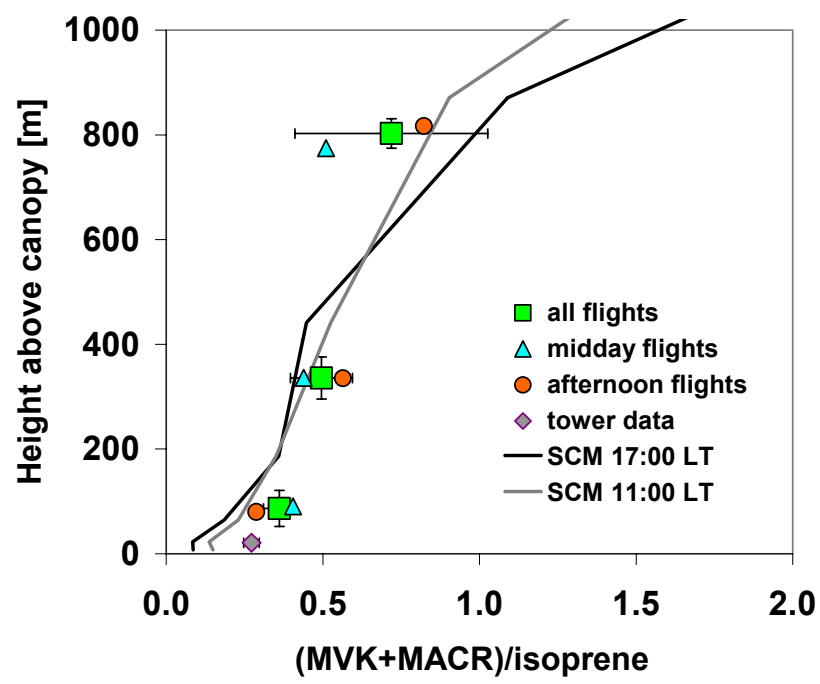

Fig. 16. Vertical profiles of (MVK+MACR)/isoprene within the CBL as in Fig. 14. The solid lines show the results of the observation-driven comprehensive SCM model for midday (11:00 LT, grey line) and afternoon (17:00 LT, black line) conditions.

the absolute mixing ratios of these compounds indicates that a state-of-the-art atmospheric chemistry model might simulate appropriate vertical profiles of the (MVK+MACR)/ISO, but for the wrong reasons, i.e. too high mixing ratios of all compounds. The $\mathrm{OH}$ concentrations in the model within the $\mathrm{CBL}$ were up to $2 \times 10^{6}$ molecules $\mathrm{cm}^{-3}$. A higher modelled $\mathrm{OH}$ concentration would result in a better representation of observed isoprene mixing ratios in the lower $\mathrm{CBL}$, and a better agreement of (MVK+MACR)/ISO close to the surface (Fig. 16). However, the overall faster depletion of reactive compounds would also affect the simulated (MVK+MACR)/ISO in higher altitudes and the vertical gradients would become stronger than in the observations.

An alternative rationale for too strong vertical gradients in the predicted ratio would be an underestimation of turbulent mixing in the model (see also von Kuhlmann et al., 2004). Due to longer chemical lifetimes compared to that of isoprene, the observed absolute mixing ratios for MVK and MACR showed relatively weak gradients (Fig. 12) compared to those of isoprene. An increase in turbulent mixing would mainly reduce the modelled isoprene gradient and thus result in a reduced gradient in (MVK+MACR)/ISO, with higher values close to the surface, and lower values in the upper regions of the CBL, thus being more representative of the observed vertical profiles of (MVK+MACR)/ISO (Fig. 16). This implies that an enhanced mixing efficiency may be required in the model to arrive at comparable absolute VOC concentrations as well as vertical gradients of (MVK+MACR)/ISO. We can not conclusively derive the different impacts of the factors influencing (MVK+MACR)/ISO. A more detailed study of the influ- ences of atmospheric chemistry and turbulent mixing on the vertical distribution of these species in the model is ongoing.

\section{Summery and conclusions}

Two tower-based micrometeorological flux techniques were used to infer the emission source strength of VOCs at a remote tropical rainforest site, and indicated reasonable agreement. The SLG approach revealed somewhat higher emission rates and a considerably higher scatter than REA, as was expected by the high degree of uncertainty of this method in complex terrain. The observed fluxes showed that VOCs may be a substantial and integral part of the regional carbon cycle. Critical limitations in the quest of quantifying the role of VOCs in the regional and global carbon budget were found in the uncertainties of both, VOC and $\mathrm{CO}_{2}$ flux estimates.

The airborne approach, using CBL vertical profiles to infer VOC fluxes, included the footprint of the tower-based measurements, but was representative of a significantly larger surface area of several hundred $\mathrm{km}^{2}$. Nevertheless, the remote tropical forest site is homogeneous upwind of the K34 tower site, with pristine rainforest dominating the large footprint area of the flight measurements. However, MLG flux estimates are influenced by the assumptions made on boundary layer turbulence dynamics and atmospheric chemistry; and the oxidation and transport time scales were found to be of similar magnitude. This leads to a coupling between CBL atmospheric chemistry and transport issues, ultimately generating conceptual and practical difficulties in estimating fluxes of reactive scalars like biogenic VOCs.

A predominance of $\mathrm{OH}$ reactions in the chemical degradation of isoprene was inferred from the observed ratios MVK/MACR within the CBL. Reaction with $\mathrm{OH}$ initiates the oxidation and removal of most trace gases, and is therefore of the greatest importance for the composition of the atmosphere. The observed vertical gradients of (MVK+MACR)/ISO were indicative of a remarkably high oxidation capacity. A simple chemical kinetics model of this ratio was used to estimate the mean $\mathrm{OH}$ concentration within the CBL, providing a best estimate of $5.5 \pm 2.5 \times 10^{6}$ molecules $\mathrm{cm}^{-3}$, which was also supported by results of a simple budget analysis based on the flux-tolifetime relationship of isoprene within the CBL. The photochemical oxidation of VOCs within the CBL contributed considerably to the shape of their vertical profiles, and neglecting chemical destruction of VOCs was shown to cause a systematic overestimate of the effective gradients applied to calculate VOC fluxes. The predominance of isoprene and its degradation products, combined with its high reactivity, is likely a key factor in the tropical CBL atmospheric chemistry, but the influence of VOCs on the oxidation capacity in models still has high uncertainties (Lelieveld et al., 2004). Current global atmospheric chemistry models tend to predict that strong VOC emissions from terrestrial ecosystems 
cause substantial reductions in tropospheric $\mathrm{OH}$ concentrations. However, the role of partly oxidized hydrocarbons and yet undetected reactive VOCs on OH chemistry is highly uncertain (Di Carlo et al., 2004). In spite of a realistic representation of the simulated isoprene surface fluxes, our SCM model analysis produced mixing ratios of isoprene and its degradation products MVK and MACR which were much higher than observations, indicative of large remaining uncertainties with respect to chemistry and transport processes. Further studies are currently conducted to help better characterize biosphere-atmosphere exchanges and the oxidation capacity of the Amazon Basin, which contains the world's largest humid forest ecosystem, much of which is undergoing profound changes due to human activities.

Acknowledgements. This study was carried out as part of the Large-Scale Atmosphere-Biosphere Experiment in Amazonia (LBA). It was made possible by support through the Max Planck Society. We greatly acknowledge the pilots for their excellent accomplishments, and the National Counsel of Technological and Scientific Development, Brazil, for their support including provision of the aircraft; and the Instituto Nacional de Pesquisas da Amazonia (INPA) for logistical support. We thank Tracey Andreae for editing the manuscript, and credit the NOAA Air Resources Laboratory for making available the HYSPLIT model, and Google Earth mapping service for providing the land cover image.

Edited by: T. Hoffmann

\section{References}

Ammann, C.: On the applicability of relaxed eddy accumulation and common methods for measuring trace gas fluxes, $\mathrm{PhD}$ thesis, Zürich, 1998.

Andreae, M. O., Artaxo, P., Brandao, C., et al.: Biogeochemical cycling of carbon, water, energy, trace gases, and aerosols in Amazonia: The LBA-EUSTACH experiments, J. Geophys. Res.Atmos., 107(D20), 8066, doi:10.1029/2001JD000524, 2002.

Andreae, M. O. and Crutzen, P. J.: Atmospheric aerosols: Biogeochemical sources and role in atmospheric chemistry, Science, 276(5315), 1052-1058, 1997.

Araujo, A. C., Nobre, A. D., Kruijt, B., et al.: Comparative measurements of carbon dioxide fluxes from two nearby towers in a central Amazonian rainforest: The Manaus LBA site, J. Geophys. Res.-Atmos., 107(D20), 8090, doi:10.1029/2001JD000676, 2002.

Baldocchi, D., Finnigan, J., Wilson, K., Paw, U. K. T., and Falge, E.: On measuring net ecosystem carbon exchange over tall vegetation on complex terrain, Bound.-Lay. Meteorol., 96(1-2), 257291, 2000.

Baldocchi, D. D.: Assessing the eddy covariance technique for evaluating carbon dioxide exchange rates of ecosystems: past, present and future, Global Change Biol., 9(4), 479-492, 2003.

Banta, R. M. and White, A. B.: Mixing-height differences between land use types: Dependence on wind speed, J. Geophys. Res.Atmos., 108(D10), 4321, doi:10.1029/2002JD002748, 2003.
Barket, D. J., Grossenbacher, J. W., Hurst, J. M., et al.: A study of the NOx dependence of isoprene oxidation, J. Geophys. Res.Atmos., 109(D11), D11310, doi:10.1029/2003JD003965, 2004.

Bey, I., Jacob, D. J., Yantosca, R. M., et al.: Global modeling of tropospheric chemistry with assimilated meteorology: Model description and evaluation, J. Geophys. Res.-Atmos., 106(D19), 23 073-23 095, 2001.

Biesenthal, T. A., Bottenheim, J. W., Shepson, P. B., and Brickell, P. C.: The chemistry of biogenic hydrocarbons at a rural site in eastern Canada, J. Geophys. Res.-Atmos., 103(D19), 25487 25 498, 1998.

Botta, A., Ramankutty, N., and Foley, J. A.: Long-term variations of climate and carbon fluxes over the Amazon basin, Geophys. Res. Lett., 29(9), 1319, 10.1029/2001GL013607, 2002.

Bowman, J. H., Barket, D. J., and Shepson, P. B.: Atmospheric chemistry of nonanal, Environmental Science \& Technology, 37(10), 2218-2225, 2003.

Brancaleoni, E., Scovaventi, M., Frattoni, M., et al.: Novel family of multi-layer cartridges filled with a new carbon adsorbent for the quantitative determination of volatile organic compounds in the atmosphere, J. Chromatogr. A, 845(1-2), 317-328, 1999.

Carter, W. P. L. and Atkinson, R.: Development and evaluation of a detailed mechanism for the atmospheric reactions of isoprene and NOx, International J. Chem. Kinet., 28(7), 497-530, 1996.

Ciccioli, P., Brancaleoni, E., and Frattoni, M.: Sampling of atmospheric volatile organic compounds (VOCs) with sorbent tubes and their analysis by GC-MS, in: Environmental Monitoring Handbook, edited by: Burden, F. R., McKelvie, I. Forstner, U., and Guenther, A., Mc Graw-Hill, New York, 2002.

Ciccioli, P., Brancaleoni, E., Frattoni, et al.: Ubiquitous Occurrence of Semivolatile Carbonyl-Compounds in Tropospheric Samples and Their Possible Sources, Atmos. Enviro., 27(12), 1891-1901, 1993.

Ciccioli, P., Brancaleoni, E., Frattoni, M., et al.: Relaxed eddy accumulation, a new technique for measuring emission and deposition fluxes of volatile organic compounds by capillary gas chromatography and mass spectrometry, J. Chromatogr. A, 985(1-2), 283-296, 2003.

Ciccioli, P., Fabozzi, C., Brancaleoni, E., et al.: Use of the isoprene algorithm for predicting the monoterpene emission from the Mediterranean holm oak Quercus ilex L.: Performance and limits of this approach, J. Geophys. Res.-Atmos., 102(D19), 23 319-23 328, 1997.

Claeys, M., Graham, B., Vas, G., et al.: Formation of secondary organic aerosols through photooxidation of isoprene, Science, 303(5661), 1173-1176, 2004.

Cleveland, C. C. and Yavitt, J. B.: Consumption of atmospheric isoprene in soil, Geophys. Res. Lett., 24(19), 2379-2382, 1997.

Culf, A. D., Fisch, G., Malhi, Y., et al.: Carbon dioxide measurements in the nocturnal boundary layer over Amazonian forest, Hydrol. Earth Syst. Sci., 3(1), 39-53, 1999.

Davis, K. J., Lenschow, D. H., and Zimmerman, P. R.: Biogenic Nonmethane Hydrocarbon Emissions Estimated from Tethered Balloon Observations, J. Geophys. Res.-Atmos., 99(D12), 25 587-25 598, 1994.

Deardorf, J.: Convective Velocity and Temperature Scales for Unstable Planetary Boundary Layer and for Rayleigh Convection, J. Atmos. Sci., 27(8), 1211-1220, 1970.

Di Carlo, P., Brune, W. H., Martinez, M., et al.: Missing OH reac- 
tivity in a forest: Evidence for unknown reactive biogenic VOCs, Science, 304(5671), 722-725, 2004.

Dias, M., Rutledge, S., Kabat, P., et al.: Cloud and rain processes in a biosphere-atmosphere interaction context in the Amazon Region, J. Geophys. Res.-Atmos., 107(D20), 8072, doi:10.1029/2001JD000335, 2002.

Dindorf, T., Kuhn U., Ganzeveld L., et al.: Significant light and temperature dependent monoterpene emissions from European beech (Fagus sylvatica L.) and their potential impact on the European volatile organic compound budget, J. Geophys. Res., 111(D16305), doi:10.1029/2005JD006751, 2006.

Do Carmo, J. B., Keller, M., Dias, J. D., et al.: A source of methane from upland forests in the Brazilian Amazon, Geophys. Res. Lett., 33(4), L04809, doi:10.1029/2005GL025436, 2006.

Donahue, N. M., Kroll, J. H., Anderson, J. G., and Demerjian, K. L.: Direct observation of $\mathrm{OH}$ production from the ozonolysis of olefins, Geophys. Res. Lett., 25(1), 59-62, 1998.

Doskey, P. V. and Gao, W. G.: Vertical mixing and chemistry of isoprene in the atmospheric boundary layer: Aircraft-based measurements and numerical modeling, J. Geophys. Res.-Atmos., 104(D17), 21 263-21 274, 1999.

Dreyfus, G. B., Schade, G. W., and Goldstein, A. H.: Observational constraints on the contribution of isoprene oxidation to ozone production on the western slope of the Sierra Nevada, California, J. Geophys. Res.-Atmos., 107(D19), 4365, doi:10.1029/2001JD001490, 2002.

Fisch, G., Tota, J., Machado, L. A. T., et al.: The convective boundary layer over pasture and forest in Amazonia, Theor. Appl. Climatol., 78(1-3), 47-59, 2004.

Fruekilde, P., Hjorth, J., Jensen, N. R., Kotzias, D., and Larsen, B.: Ozonolysis at vegetation surfaces: A source of acetone, 4oxopentanal, 6-methyl-5-hepten-2-one, and geranyl acetone in the troposphere, Atmos. Environ., 32(11), 1893-1902, 1998.

Fuentes, J. D., Lerdau, M., Atkinson, R., et al.: Biogenic hydrocarbons in the atmospheric boundary layer: A review, B. Am. Meteor. Soc., 81(7), 1537-1575, 2000.

Galbally, I. E. and Kirstine, W.: The production of methanol by flowering plants and the global cycle of methanol, J. Atmos. Chem., 43(3), 195-229, 2002.

Ganzeveld, L., Klemm, O., Rappenglück, B., and ValverdeCanossa, J.: Evaluation of Micrometeorology over a Coniferous Forest in a Single-Column Chemistry-Climate Model, Atmos. Environ., 40, Suppl. 1, 21-27, 2006 a.

Ganzeveld, L. and Lelieveld, J.: Impact of Amazonian deforestation on atmospheric chemistry, Geophys. Res. Lett., 31(6), L06105, doi:10.1029/2003GL019205, 2004.

Ganzeveld, L., Valverde-Canossa, J., Moortgat, G., and Steinbrecher, R.: Evaluation of Peroxide Exchanges over a Coniferous Forest in a Single-Column Chemistry-Climate Model, Atmos. Environ., 40, Suppl. 1, 68-80, 2006 b.

Ganzeveld, L. N., Lelieveld, J., Dentener, F. J., Krol, M. C., and Roelofs, G. J.: Atmosphere-biosphere trace gas exchanges simulated with a single-column model, J. Geophys. Res.-Atmos., 107(D16), 4297, doi:10.1029/2001JD000684, 2002.

Garratt, J. R.: Surface influence upon vertical profiles in the atmospheric nearsurface layer, Q. J. Roy. Meteor. Soc., 106, 803-819, 1980.

Garstang, M., Scala, J., Greco, S., et al.: Trace Gas Exchanges and Convective Transports over the Amazonian Rain-Forest, J. Geo- phys. Res.-Atmos., 93(D2), 1528-1550, 1988.

Geron, C., Guenther, A., Greenberg, J., Loescher, H. W., Clark, D., and Baker, B.: Biogenic volatile organic compound emissions from a lowland tropical wet forest in Costa Rica, Atmos. Environ., 36(23), 3793-3802, 2002.

Goldan, P. D., Parrish, D. D., Kuster, W. C., et al.: Airborne measurements of isoprene, $\mathrm{CO}$, and anthropogenic hydrocarbons and their implications, J. Geophys. Res.-Atmos., 105(D7), 90919105, 2000.

Goldstein, A .H., McKay, M., Kurpius, M. R., et al.: Forest thinning experiment confirms ozone deposition to forest canopy is dominated by reaction with biogenic VOCs, Geophys. Res. Lett., 31, L22106, doi:10.1029/2004GL021259, 2004.

Goldstein, A. H. and Galbally, I. E.: Known and unexplored organic constituents in the earth's atmosphere, Environ. Sci. Technol., 41, 5, 1515-1521, 2007.

Greenberg, J. P., Guenther, A., Zimmerman, P., et al.: Tethered balloon measurements of biogenic VOCs in the atmospheric boundary layer, Atmos. Environ., 33(6), 855-867, 1999.

Greenberg, J. P., Guenther, A. B., Petron, G., et al.: Biogenic VOC emissions from forested Amazonian landscapes, Global Change Biol., 10(5), 651-662, 2004.

Grosjean, D.: Atmospheric Chemistry of Biogenic Hydrocarbons Relevance to the Amazon, Quimica Nova, 18(2), 184-201, 1995.

Guenther, A.: The contribution of reactive carbon emissions from vegetation to the carbon balance of terrestrial ecosystems, Chemosphere, 49(8), 837-844, 2002.

Guenther, A., Hewitt, C. N., Erickson, D., et al.: A global-model of natural volatile organic-compound emissions, J. Geophys. Res.Atmos., 100(D5), 8873-8892, 1995.

Helmig, D., Balsley, B., Davis, K., et al.: Vertical profiling and determination of landscape fluxes of biogenic nonmethane hydrocarbons within the planetary boundary layer in the Peruvian Amazon, J. Geophys. Res.-Atmos., 103(D19), 25 519-25 532, 1998.

Helmig, D., Pollock, W., Greenberg, J., and Zimmerman, P.: Gas chromatography mass spectrometry analysis of volatile organic trace gases at Mauna Loa observatory, Hawaii, J. Geophys. Res.Atmos., 101(D9), 14 697-14 710, 1996.

Holzinger, R., Williams, J., Salisbury, G., et al.: Oxygenated compounds in aged biomass burning plumes over the Eastern Mediterranean: evidence for strong secondary production of methanol and acetone, Atmos. Chem. Phys., 5, 39-46, 2005, http://www.atmos-chem-phys.net/5/39/2005/.

Hicks, B. B., Baldocchi, D. D., Meyers, T. P., Hosker, R. P., and Matt, D. R.: A Preliminary Multiple Resistance Routine for Deriving Dry Deposition Velocities from Measured Quantities, Water Air Soil Poll., 36(3-4), 311-330, 1987.

Higuchi, N., Santos, J., Vieira, G., et al.: Plant structural analysis of a pristine tropical moist forest in Cuieiras river basin region, ZF-2, Manaus-AM, Brazil, in: Pesquisas florestais para a conservacao e reabilitacao de areas degradadas da Amazonia, edited by: Higuchi, N., Campos, M. A. A., Sampaio, P. T. B., and Santos, J., Instituto Nacional de Pesquisas da Amazonia, Manaus, Brazil, 53-81, 1998.

Hodnett, M. G., Oyama, M. D., Tomasella, J., and Filho, A. M.: Comparisons of long-term soil water storage behaviour under pasture and forest in the three areas of Amazonia, in: Amazon Deforestation and Climate, edited by: Gash, J. H. C. , Nobre C. 
A., Roberts, J. M., and Victoria, R. L., John Wiley, New York, 57-77, 1996.

Ieda, T., Kitamori, Y., Mochida, M., et al.: Diurnal variations and vertical gradients of biogenic volatile and semi-volatile organic compounds at the Tomakomai larch forest station in Japan, Tellus Ser. B, 58(3), 177-186, 2006.

Jardim, F. C. S. and Hosokawa R. T.: Estrutura da floresta equatorial umida da estacao experimental de silvicultura tropical do INPA, Acta Amazonica, 16/17, 411-508, 1987.

Karl, T., Potosnak, M., Guenther, A., et al.: Exchange processes of volatile organic compounds above a tropical rain forest: Implications for modeling tropospheric chemistry above dense vegetation, J. Geophys. Res.-Atmos., 109(D18), D18306, doi:10.1029/2004JD004738, 2004.

Karl, T., Guenther, A., Greenberg, J., Yokelson, R. J., Blake, D. R., Potosnak, M., and Artaxo, P.: Emission, Chemistry, and Transport of Biogenic Volatile Organic Compounds in the Lower Atmosphere over Amazonia J. Geophys. Res., in press, 2007.

Keppler, F., Hamilton, J. T. G., Brass, M., and Rockmann, T.: Methane emissions from terrestrial plants under aerobic conditions, Nature, 439(7073), 187-191, 2006.

Kesselmeier, J., Ciccioli, P., Kuhn, U., et al.: Volatile organic compound emissions in relation to plant carbon fixation and the terrestrial carbon budget, Global Biogeochem. Cycles, 16(4), 1126, doi:10.1029/2001GB001813, 2002a.

Kesselmeier, J., Kuhn, U., Rottenberger, S., et al.: Concentrations and species composition of atmospheric volatile organic compounds (VOCs) as observed during the wet and dry season in Rondonia (Amazonia), J. Geophys. Res.-Atmos., 107(D20), 8053, 8053, doi:10.1029/2000JD000267, 2002b.

Kesselmeier, J., Kuhn, U., Wolf, A., et al.: Atmospheric volatile organic compounds (VOC) at a remote tropical forest site in central Amazonia, Atmos. Environ., 34(24), 4063-4072, 2000.

Kesselmeier, J., Schafer, L., Ciccioli, P., et al.: Emission of monoterpenes and isoprene from a Mediterranean oak species Quercus ilex L measured within the BEMA (Biogenic Emissions in the Mediterranean Area) project, Atmos. Environ., 30(10-11), 1841-1850, 1996.

Kirstine, W., Galbally, I., Ye, Y. R., and Hooper, M.: Emissions of volatile organic compounds (primarily oxygenated species) from pasture, J. Geophys. Res.-Atmos., 103(D9), 10 605-10 619, 1998.

Kleffmann, J., Gavriloaiei, T., Hofzumahaus, A., et al.: Daytime formation of nitrous acid: A major source of $\mathrm{OH}$ radicals in a forest, Geophys. Res. Lett., 32(5), L05818, doi:10.1029/2005GL022524, 2005.

Kleinman, L. I., Daum, P. H., Imre, D., et al.: Ozone production rate and hydrocarbon reactivity in 5 urban areas: A cause of high ozone concentration in Houston, Geophys. Res. Lett., 29(10), 1467, doi:10.1029/2001GL014569, 2002.

Klinge, H., Rodrigues, W. A., Bruning, E., and Fittkau, E. J.: Biomass and structure in a central Amazon rainforest, in: Tropical Ecology Systems: Trends in terrestrial and aquatic research, edited by: Golley, F. B. and Medina, E., Springer-Verlag, New York, 1975.

Krol, M. C., Molemaker, M. J., de Arellano, J. V. G.: Effects of turbulence and heterogeneous emissions on photochemically active species in the convective boundary layer, J. Geophys. Res.Atmos., 105(D5), 6871-6884, 2000.
Kroll, J. H., Donahue, N. M., Cee, V. J., Demerjian, K. L., and Anderson, J. G.: Gas-phase ozonolysis of alkenes: Formation of OH from anti carbonyl oxides, J. Am. Chem. Soc., 124(29), 8518-8519, 2002.

Kruijt, B., Elbers, J. A., von Randow, C., et al.: The robustness of eddy correlation fluxes for Amazon rain forest conditions, Ecol. Appl., 14(4), 101-113, 2004.

Kruijt, B., Lloyd, J., Grace, J., et al.: Sources and sinks of $\mathrm{CO}_{2}$ in Rondonia tropical rainforest, in: Amazonian Deforestation and Climate, edited by: Gash, J., Nobre, C., Robers, J., and Victoria, R., John Wiley, Chichester, pp. 331-351, 2000.

Kuhn, U., Dindorf, T., Ammann, C., et al.: Design and field application of an automated cartridge sampler for VOC concentration and flux measurements, J Environ. Monitor., 7(6), 568-576, 2005.

Kuhn, U., Rottenberger, S., Biesenthal, T., et al.: Isoprene and monoterpene emissions of Amazonian tree species during the wet season: Direct and indirect investigations on controlling environmental functions, J. Geophys. Res.-Atmos., 107(D20), 8071, doi:10.1029/2001JD000978, 2002.

Kuhn, U., Rottenberger, S., Biesenthal, T., et al.: Seasonal differences in isoprene and light-dependent monoterpene emission by Amazonian tree species, Global Change Biol., 10(5), 663-682, 2004a.

Kuhn, U., Rottenberger, S., Biesenthal, T., Wolf, A., Schebeske, G., Ciccioli, P., and Kesselmeier, J.: Strong correlation between isoprene emission and gross photosynthetic capacity during leaf phenology of the tropical tree species Hymenaea courbaril with fundamental changes in VOC emission composition during early leaf development, Plant Cell \& Environ., 27(12), doi:10.1111/j.1365-3040.2004.01252.x, 2004b

Lelieveld, J., Dentener, F. J., Peters, W., and Krol, M. C.: On the role of hydroxyl radicals in the self-cleansing capacity of the troposphere, Atmos. Chem. Phys., 4, 2337-2344, 2004, http://www.atmos-chem-phys.net/4/2337/2004/.

Lelieveld, J., Peters, W., Dentener, F. J., and Krol, M. C.: Stability of tropospheric hydroxyl chemistry, J. Geophys. Res.-Atmos., 107(D23), 4715, doi:10.1029/2002JD002272, 2002.

Lenschow, D. H. and Stankov, B. B.: Length Scales in the Convective Boundary-Layer, J. Atmos. Sci., 43(12), 1198-1209, 1986.

Lenschow, D. H., Wyngaard, J. C., and Pennell, W. T.: Mean-Field and 2nd-Moment Budgets in a Baroclinic, Convective BoundaryLayer, J. Atmos. Sci., 37(6), 1313-1326, 1980.

Lloyd, J., Langenfelds, R. L., Francey, R. J., et al.: A trace-gas climatology above Zotino, central Siberia, Tellus Ser. B, 54(5), 749-767, 2002.

Lloyd, J. K. O., Fritsch H., Freitas De, S. R., et al.: Airborne Estimates of the Amazon Carbon Balance, Biogeosciences Discuss., 4, 99-123, 2007,

http://www.biogeosciences-discuss.net/4/99/2007/.

Malhi, Y., Nobre, A. D., Grace, J., Kruijt, B., Pereira, M. G. P., Culf, A., and Scott, S.: Carbon dioxide transfer over a Central Amazonian rain forest, J. Geophys. Res.-Atmos., 103(D24), 31 593$31612,1998$.

Malhi, Y., Phillips, O. L., Lloyd, J., et al.: An international network to monitor the structure, composition and dynamics of Amazonian forests (RAINFOR), J. Veg. Sci., 13(3), 439-450, 2002.

Martens, C. S., Shay, T. J., Mendlovitz, H. P., et al.: Radon fluxes in tropical forest ecosystems of Brazilian Amazonia: night-time 
$\mathrm{CO} 2$ net ecosystem exchange derived from radon and eddy covariance methods, Global Change Biol., 10(5), 618-629, 2004.

Matsunaga, S., Mochida, M., and Kawamura, K.: Growth of organic aerosols by biogenic semi-volatile carbonyls in the forestal atmosphere, Atmos. Environ., 37(15), 2045-2050, 2003.

McWilliam, A.-L., Roberts, J., Cabral, O., et al.: Leaf area index and aboveground biomass of terra firme rain forest and adjecent clearings in Amazonia, Funct. Ecol., 7, 310-317, 1993.

Moise, T. and Rudich, Y.: Reactive uptake of ozone by aerosolassociated unsaturated fatty acids: Kinetics, mechanism, and products, J. Phys. Chem. A, 106(27), 6469-6476, 2002.

Montzka, S. A., Trainer, M., Angevine, W. M., and Fehsenfeld, F. C.: Measurements of 3-Methyl Furan, Methyl Vinyl Ketone, and Methacrolein at a Rural Forested Site in the Southeastern UnitedStates, J. Geophys. Res.-Atmos., 100(D6), 11 393-11 401, 1995.

Moortgat, G. K.: Important photochemical processes in the atmosphere, Pure Appl. Chem., 73(3), 487-490, 2001.

Ometto, J., Nobre, A. D., Rocha, H. R., Artaxo, P., and Martinelli, L. A.: Amazonia and the modern carbon cycle: lessons learned, Oecologia, 143(4), 483-500, 2005.

Owen, S., Boissard, C., Street, R. A., et al.: Screening of 18 Mediterranean plant species for volatile organic compound emissions, Atmos. Environ., 31, 101-117, 1997.

Patton, E. G., Sullivan, P. P., and Davis, K. J.: The influence of a forest canopy on top-down and bottom-up diffusion in the planetary boundary layer, Q. J. Roy. Meteor. Soc., 129(590), 1415-1434, 2003.

Paulson, S. E. and Orlando, J. J.: The reactions of ozone with alkenes: An important source of HOx in the boundary layer, Geophys. Res. Lett., 23(25), 3727-3730, 1996.

Paulson, S. E., Sen, A. D., Liu, P., Fenske, J. D., and Fox, M. J.: Evidence for formation of $\mathrm{OH}$ radicals from the reaction of $\mathrm{O}-3$ with alkenes in the gas phase, Geophys. Res. Lett., 24(24), 31933196, 1997.

Pfeiffer, T., Forberich, O., and Comes, F. J.: Tropospheric OH formation by ozonolysis of terpenes, Chemi. Phys. Lett., 298(4-6), 351-358, 1998.

Poisson, N., Kanakidou, M., and Crutzen, P. J.: Impact of nonmethane hydrocarbons on tropospheric chemistry and the oxidizing power of the global troposphere: 3-dimensional modelling results, J. Atmos. Chem., 36(2), 157-230, 2000.

Poschl, U., von Kuhlmann, R., Poisson, N., and Crutzen, P. J.: Development and intercomparison of condensed isoprene oxidation mechanisms for global atmospheric modeling, J. Atmos. Chem., 37(1), 29-52, 2000.

Rasmussen, R. A. and Khalil, M. A. K.: Isoprene over the Amazon Basin, J. Geophys. Res.-Atmos., 93(D2), 1417-1421, 1988.

Ribeiro, J. D. S., Hopkins, M., Vicentini, A., et al.: Flora da Reserva Ducke: Guia de identificacao das plantas vasculares de uma floresta de terra-firme na Amazonia Central., INPA, Manaus, 1999.

Rinne, H. J. I., Guenther, A. B., Greenberg, J. P., and Harley, P. C.: Isoprene and monoterpene fluxes measured above Amazonian rainforest and their dependence on light and temperature, Atmos. Environ., 36(14), 2421-2426, 2002.

Roberts, J. M., Cabral, O. M. R., da Costa, J. P., et al.: An overview of the leaf area index and physiological measurements during ABRACOS, in: Amazonian Deforestation and Climate, edited by: Gash, J.C., Nobre, C., Roberts, J. M., and Vitoria, R. L., John Wiley, New York, pp. 287-306, 1996.
Roelofs, G. J. and Lelieveld, J.: Tropospheric ozone simulation with a chemistry-general circulation model: Influence of higher hydrocarbon chemistry, J. Geophys. Res.-Atmos., 105(D18), 22 697-22 712, 2000.

Ryerson, T. B., Trainer, M., Holloway, J. S., et al.: Observations of ozone formation in power plant plumes and implications for ozone control strategies, Science, 292(5517), 719-723, 2001.

Saunders, S. M., Jenkin, M. E., Derwent, R. G., and Pilling, M. J.: Protocol for the development of the Master Chemical Mechanism, MCM v3 (Part A): tropospheric degradation of nonaromatic volatile organic compounds, Atmos. Chem. Phys., 3, 161-180, 2003, http://www.atmos-chem-phys.net/3/161/2003/.

Serca, D., Guenther, A., Klinger, L., et al.: EXPRESSO flux measurements at upland and lowland Congo tropical forest site, Tellus Ser. B, 53(3), 220-234, 2001.

Simon, E., Lehmann, B. E., Ammann, C., et al.: Lagrangian dispersion of Rn-222, $\mathrm{H} 2 \mathrm{O}$ and $\mathrm{CO} 2$ within Amazonian rain forest Agr. Forest Meteorol., 132(3-4), 286-304, 2005.

Spirig, C., Guenther, A., Greenberg, J. P., Calanca, P., and Tarvainen, V.: Tethered balloon measurements of biogenic volatile organic compounds at a Boreal forest site, Atmos. Chem. Phys., 4, 215-229, 2004, http://www.atmos-chem-phys.net/4/215/2004/.

Spirig, C., Neftel, A., Ammann, C., et al.: Eddy covariance flux measurements of biogenic VOCs during ECHO 2003 using proton transfer reaction mass spectrometry, Atmos. Chem. Phys., 5, 465-481, 2005, http://www.atmos-chem-phys.net/5/465/2005/.

Staebler, R. M. and Fitzjarrald, D. R.: Observing subcanopy CO2 advection, Agr. Forest Meteorol., 122(3-4), 139-156, 2004.

Staudt, M. and Seufert, G.: Light-Dependent Emission of Monoterpenes by Holm Oak (Quercus-Ilex L), Naturwissenschaften, 82(2), 89-92, 1995.

Stroud, C., Makar, P., Karl, T., et al.: Role of canopyscale photochemistry in modifying biogenic-atmosphere exchange of reactive terpene species: Results from the CELTIC field study, J. Geophys. Res.-Atmos., 110(D17), D17303, doi:10.1029/2005JD005775, 2005.

Stroud, C. A., Roberts, J. M., Goldan, P. D., et al.: Isoprene and its oxidation products, methacrolein and methylvinyl ketone, at an urban forested site during the 1999 Southern Oxidants Study, J. Geophys. Res.-Atmos., 106(D8), 8035-8046, 2001.

Stull, R. B.: An introduction to boundaty layer meteorology, Kluwer Academic Publishers, Dordrecht, 1988.

Tan, D., Faloona, I., Simpas, J. B., et al.: HOx budgets in a deciduous forest: Results from the PROPHET summer 1998 campaign, J. Geophys. Res.-Atmos., 106(D20), 24 407-24 427, 2001.

Tian, H. Q., Melillo, J. M., Kicklighter, D. W., et al.: Effect of interannual climate variability on carbon storage in Amazonian ecosystems, Nature, 396(6712), 664-667, 1998.

Trainer, M., Williams, E. J., Parrish, D. D., et al.: Models and Observations of the Impact of Natural Hydrocarbons on Rural Ozone, Nature, 329(6141), 705-707, 1987.

Trostdorf, C. R., Gatti, L. V., Yamazaki, A., et al.: Seasonal cycles of isoprene concentrations in the Amazonian rainforest, Atmos. Chem. Phys. Discuss., 4, 1291-1310, 2004, http://www.atmos-chem-phys-discuss.net/4/1291/2004/.

Tuazon, E. C. and Atkinson, R.: A Product Study of the Gas-Phase 
Reaction of Isoprene with the $\mathrm{OH}$ Radical in the Presence of NOx, In. J. Chem. Kinet., 22(12), 1221-1236, 1990.

Valentini, R., Greco, S., Seufert, G., Bertin, N., Ciccioli, P., Cecinato, A., Brancaleoni, E., and Frattoni, M.: Fluxes of biogenic VOC from Mediterranean vegetation by trap enrichment relaxed eddy accumulation, Atmos. Environ., 31, Suppl. 1, 229238, 1997.

von Kuhlmann, R.: Tropospheric photochemistry of ozone, its precursors and the hydroxyl radical: A 3D-modeling study considering non-methane hydrocarbons, PhD thesis, Johannes Gutenberg-Universität, Mainz, Germany, 2001.

von Kuhlmann, R., Lawrence, M. G., Poschl, U., and Crutzen, P. J.: Sensitivities in global scale modeling of isoprene, Atmos. Chem. Phys., 4, 1-17, 2004,

http://www.atmos-chem-phys.net/4/1/2004/.

Warneke, C., Holzinger, R., Hansel, A., et al.: Isoprene and its oxidation products methyl vinyl ketone, methacrolein, and isoprene related peroxides measured online over the tropical rain forest of Surinam in March 1998, J. Atmos. Chem., 38(2), 167-185, 2001.
Wildt, J., Kobel, K., Schuh-Thomas, G., and Heiden, A. C.: Emissions of oxygenated volatile organic compounds from plants - part II: Emissions of saturated aldehydes, J. Atmos. Chem., 45(2), 173-196, 2003.

Williams, J., Fischer, H., Harris, G. W., et al.: Variability-lifetime relationship for organic trace gases: A novel aid to compound identification and estimation of HO concentrations, J. Geophys. Res.-Atmos., 105(D16), 20 473-20 486, 2000.

Williams, J., Poschl, U., Crutzen, P. J., et al.: An atmospheric chemistry interpretation of mass scans obtained from a proton transfer mass spectrometer flown over the tropical rainforest of Surinam, J. Atmos. Chem., 38(2), 133-166, 2001.

Zimmerman, P. R., Greenberg, J. P., and Westberg, C. E.: Measurements of Atmospheric Hydrocarbons and Biogenic Emission Fluxes in the Amazon Boundary-Layer, J. Geophys. Res.Atmos., 93(D2), 1407-1416, 1988. 